\title{
A STUDY OF BURNS AND SCALDS IN CHILDREN
}

\author{
BY \\ BRENDA MORRISON, M.D. \\ (From the Children's Department, Royal Victoria Infirmary, Newcastle-on-Tyne)
}

The problem of burns and scalds in children has been materially altered during the past five or six years by the fact that human plasma and serum have become available for treatment. This means not only that many lives can now be saved which previously were lost, but also that new problems arise from the survival of children with serious and extensive lesions. In short, resuscitation has so advanced beyond other aspects of therapy that it is possible to keep alive for several weeks or months children who stand little chance of ultimate recovery. The assessment of this chance of recovery and the decision that must be taken at the very beginning as to whether or not resuscitation should be attempted, is often very difficult. It appears that, with only ordinary hospital facilities available, cases with lesions affecting more than 40 per cent. of the body surface do not survive beyond a few weeks; with specially equipped units this could almost certainly be improved upon (Bourdillon and Colebrook, 1946). On the other hand, small children can die from fluid loss when the local lesion is neither deep nor extensive, and in this type of case plasma therapy has altered the outlook completely. There is no need now for any child over the age of one year to die from a lesion involving less than 30 per cent. of the body surface.

The following study was undertaken in the hope of obtaining a better understanding of the problems that arise during the routine hospital treatment of burned and scalded children, and to determine the most reliable criteria for its guidance.

\section{Case Material}

Between June, 1943 and March, 1946 a series of thirty-one cases of accidental burns (seventeen cases) and scalds (fourteen cases) were studied by close clinical observation and by simple haematological and biochemical investigations. Table 1 shows age and sex, time of admission to hospital after injury, the nature, extent, and degree of the injuries, and the ultimate outcome in death or recovery.

The injuries occurred in the home except in two cases, that of a girl burned in a bonfire and that of a boy whose clothes caught fire while he was climbing an electric pylon. In sixteen cases the burns were caused by clothing catching fire. A detailed social enquiry was not made, but it was evident that absence of fireguards and lack of space where children can play away from the kitchen hearth were important causal factors, particularly in cold weather. This aspect of the problem has been stressed recently by Colebrook (1946). Nearly all the scalds (twelve out of fourteen) occurred in children under five years, and nearly all the burns (fourteen out of seventeen) in children over five years.

These cases form a selected group in that they all required admission to hospital and showed constitutional disturbance of varying degree. Their ages ranged from one to ten years; half were under five and one-third under three years. The data here considered are more complete for the older than for the younger children as the latter are difficult to study because of lack of co-operation and difficulties of venepuncture. They are, however, liable to severe constitutional disturbance without either very extensive or very deep lesions, and in them prompt and energetic treatment is most important and most rewarding.

The injuries. In estimating the extent of the injuries, the following division of body surface was used:
Head and néck
15 per cent.
Both arms and shoulders 15 per cent.
Trunk (to groin level) 40 per cent.
Both legs and thighs 30 per cent.

In most cases photographs or diagrams were made so that the initial estimate of the extent of the lesions could be checked by later observation.

The lesions are classified according to Dupuytren's seven degrees. This may appear to result in unnecessary subdivision, but it is of value for the prognosis of the lesions and also there is a significant relationship between the subdivisions and the constitutional disturbance. No discrimination is made between burns and scalds, as their difference is one of degree only; in very young children complete skin loss may be caused by boiling water. The following is the classification :

First degree. Erythema, which clears up in two to three days with no more than a scaling of the 
TABLE 1

THIRTY-ONE CASES OF ACCIDENTAL BURNS AND SCALDS

\begin{tabular}{|c|c|c|c|c|c|c|c|}
\hline $\begin{array}{l}\dot{\alpha} \\
\dot{z} \\
\dot{g} \\
\end{array}$ & $\stackrel{8}{4}$ & ๖ & 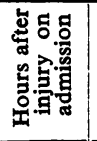 & in & 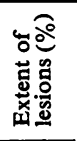 & $\begin{array}{l}\stackrel{\Xi}{ \pm} \\
\stackrel{\Xi}{\Xi}\end{array}$ & 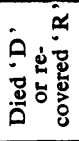 \\
\hline 1 & 4 & $\mathbf{F}$ & 24 & $\mathbf{S}$ & 15 & 2,3 & $\mathbf{R}$ \\
\hline 2 & 7 & $\mathbf{F}$ & 72 & $\mathbf{S}$ & 6 & 3 & $\mathbf{R}$ \\
\hline 3 & 6 & $\mathbf{F}$ & $3 \frac{1}{2}$ & $\mathbf{S}$ & 15 & 2,3 & $\mathbf{R}$ \\
\hline 4 & 2 & $\mathbf{F}$ & 2 & $\mathbf{S}$ & 5 & 3 & $\mathbf{R}$ \\
\hline 5 & $1 \frac{1}{2}$ & $\mathbf{M}$ & 2 & $\mathbf{S}$ & 12 & 2,3 & $\mathbf{R}$ \\
\hline 6 & 8 & $\mathbf{F}$ & $3 \frac{1}{2}$ & B & 60 & 4,3 & D \\
\hline 7 & $1 \frac{3}{4}$ & $\mathbf{M}$ & $1 \frac{1}{2}$ & $\mathbf{S}$ & 33 & 3,4 & $\mathbf{R}$ \\
\hline 8 & 2 & $\mathbf{M}$ & 2 & $\mathbf{S}$ & 10 & 3,4 & $\mathbf{R}$ \\
\hline 9 & 1 & $\mathbf{F}$ & 2 & $\mathbf{S}$ & 20 & 2,3 & $\mathbf{R}$ \\
\hline 10 & 2 & $F$ & 2 & $\mathbf{S}$ & 20 & 3 & $\mathbf{R}$ \\
\hline 11 & 5 & $\mathbf{M}$ & $\frac{1}{2}$ & B & 20 & 4 & $\mathbf{R}$ \\
\hline 12 & $2 \frac{1}{2}$ & $\mathrm{~F}$ & 5 & B & 20 & 3,4 & $\mathbf{R}$ \\
\hline 13 & 2 & $\mathbf{F}$ & 2 & $S$ & 20 & 2,3 & $\mathbf{R}$ \\
\hline 14 & 10 & $\mathbf{F}$ & $\frac{1}{2}$ & B & 30 & 4,5 & $\mathbf{R}$ \\
\hline 15 & 5 & $F$ & $3 \frac{1}{2}$ & B & 60 & 4,3 & D \\
\hline 16 & 8 & $F$ & 2 & B & 40 & 4,5 & D \\
\hline 17 & 6 & $\mathbf{M}$ & 4 & B & 75 & 4,5 & D \\
\hline 18 & 9 & $\mathrm{~F}$ & $1 \frac{1}{2}$ & B & 12 & 3,4 & $\mathbf{R}$ \\
\hline$\overline{19}$ & 10 & $\mathbf{M}$ & 20 & B & 7 & 3,4 & $\mathbf{R}$ \\
\hline 20 & 10 & $\mathbf{M}$ & $1 \frac{1}{2}$ & B & 50 & $4,5,6$ & D \\
\hline 21 & 5 & $\mathbf{F}$ & 1 & B & 15 & 3,4 & $\mathbf{R}$ \\
\hline 22 & 7 & $F$ & 1 & B & 30 & 3,4 & $\mathbf{R}$ \\
\hline 23 & $3 \frac{1}{2}$ & $F$ & 2 & B & 30 & 4,5 & $\mathbf{R}$ \\
\hline 24 & 31 & $\mathbf{M}$ & 1 & $\mathbf{S}$ & 12 & 2,3 & $\mathbf{R}$ \\
\hline 25 & $2 \frac{3}{4}$ & $\mathbf{M}$ & 2 & $\mathbf{S}$ & 20 & 3 & $\mathbf{R}$ \\
\hline 26 & 3 & $\mathbf{F}$ & & B & 60 & 4,5 & $\mathbf{D}$ \\
\hline 27 & $10 \frac{1}{2}$ & $\mathbf{F}$ & 1 & B & 40 & 4 & $\mathbf{D}$ \\
\hline$\overline{28}$ & 5 & $\mathbf{F}$ & 1 & B & 35 & 4,5 & $\mathbf{R}$ \\
\hline 29 & 3 & $\mathbf{M}$ & $2 \frac{1}{2}$ & $\mathbf{S}$ & 15 & 3,4 & $\mathbf{R}$ \\
\hline 30 & 2 & $\mathbf{M}$ & 2 & $\mathbf{S}$ & 30 & 3,4 & $\mathbf{R}$ \\
\hline 31 & 5 & $\mathbf{F}$ & 1 & B & 25 & 4,5 & $\mathbf{R}$ \\
\hline
\end{tabular}

stratum corneum of the epidermis, such as is seen after mild sunburning. Apart from the pain produced, the lesion may be disregarded. There is no oozing and no sloughing.

Second degree. Small unbroken blisters or the edges of large blisters. Here there is separation of the superficial epidermal layers from the stratum germinativum by exudate, but the basal layer is intact and healing is complete (in the absence of infection) in ten to fourteen days. A reddening of the skin which fades after a few weeks or months is all that remains. There is no sloughing or scarring. Initial fluid loss from such lesions is not great, and the exudate tends to coagulate after a few hours into a compact jelly.

Third degree. The cuticle is loose and torn or absent; fluid oozes freely from the exposed red area. No white or yellow patches are visible initially, but after several days the lesion comes to have an appearance simulating the strawberry tongue of scarlet fever. There is a thin whitish slough of dead epithelial cells through which the red tops of the exposed vascular dermal papillae are seen. In many areas the whole thickness of the epithelium has been killed, though multiple small islands of it persist between the dermal papillae and around hair follicles and sweat glands. The epithelium, in the absence of infection, will proliferate from these islands and cover the neighbouring areas so that complete healing can occur without grafting. This process takes from three to six weeks. It leaves a rather irregular epithelial surface but no contractures; movement is good.

Fourth degree. There is death of all the epithelium and of more or less of the dermis. Such lesions can be recognized initially by the presence of a white area insensitive to pin prick and from which no oozing occurs. They are surrounded by red oozing areas. Though oozing does not occur from the ischaemic coagulated areas, much fluid exudes from the vessels of the less damaged tissues beneath. Thus, swelling is usually great and the white dry coagulated patch is raised well above the surrounding skin. Sloughing follows, and, depending upon the depth and area of the dead tissue, the time taken for separation is between three and six weeks. It is to be remembered that the presence of a 'purulent' exudate during separation does not necessarily indicate secondary infection. The sloughs, when loose, can be removed with little trauma and have the appearance and texture of chamois leather. After separation, there is left a granulating surface which has no epithelial elements apart from an occasional island growing from a hair follicle or sweat gland. Because inward growth from the edges of the lesion is slow, grafting is required in any sizeable lesion to prevent gross scarring and contracture.

Fifth degree. This is a further stage of the preceding in which the subcutaneous fat is involved, 
and separation of the slough occurs through this layer. It can be suspected initially by a parchment or leathery feel of the coagulated skin and by the charred cuticle. Subcutaneous fluid loss is again gross. The sloughs tend to remain drier and harder and to separate earlier and more readily than in the fourth-degree lesions, and the deeper part of the fat is then exposed, often with the remains of coagulated blood vessels in it. This surface granulates and grafting is again essential.

Sixth and seventh degrees. These, which extend to muscle and bone, are seldom seen unless the victim is burned to death. However, electric burns are nearly always very deep and involve muscle frequently and bone quite often. The central core of shrivelled tissue becomes depressed beneath the level of the surrounding less damaged but much swollen tissues.

It is to be emphasized that to the inexpert the appearance of any burn or scald within a few hours of injury is deceptively favourable. It is not until about the tenth day that the area of dead tissue is well defined, and then it is often greatly in excess of what at first seemed likely. But if attention is paid to the details of the lesions, as given above, it is usually possible to foretell from the early stages which areas will later require grafting; in particular it is essential to realize that the presence, immediately after burning, of white patches or mottling in a red area means the complete loss of the epithelium, and that the presence of white insensitive skin inside a red area means that the whole thickness of epidermis and dermis is necrosed and will slough.

\section{Clinical Features Observed}

For the first few days observations were made frequently. Blood pressure, pulse or heart rate, and respiration rate were noted every fifteen to thirty minutes for five or six hours, then hourly for a similar period; later three or four times a day and so on as the child's state became stabilized and controlled. Temperature was taken fourhourly, sometimes two-hourly in the initial stages. It was measured in the mouth, or in the rectum if the child was irrational or under three years. Other features closely watched included mental alertness, restlessness, co-operation, pain, thirst, vomiting, sweating, skin colour and temperature, and the degree of oozing from the burned areas. Difficulty was found in measuring fluid intake and output because of vomiting, frequent bed wetting, and unknown loss in the dressings. The urine was examined in all cases.

Blood pressure. For blood pressure estimation a sphygmomanometer cuff with a rubber bag 8.5 by $23 \mathrm{~cm}$. was used for most of the children, and one of 7 by $21 \mathrm{~cm}$. for the babies, these being the correct cuff sizes as determined by Robinow et al. (1939). A series of observations (unpublished) on normal children was made in this department using these cuffs. Repeated readings were taken at five-minute intervals until a steady level was reached; by then the children often had fallen asleep. So estimated, blood pressure varies little throughout childhood and is about $100 / 70 \mathrm{~mm}$. Hg. The value for the systolic pressure agrees with that found by Robinow and others (1939) using an intra-arterial manometer. The diastolic level is 5 to $10 \mathrm{~mm}$. higher than that given by these writers. In the burned and scalded children, estimates of blood pressure and pulse rate were regarded as significant only when they could be obtained with the child quiet and co-operative; only such readings are included here. In many cases, the blood pressure could not be reliably estimated after the first week or ten days owing to the child's fear of being handled at this stage and consequent crying and struggling.

BloOD Examination, ETC. Examination of the blood provides data for estimating the fluid lost from the circulation. Where possible, venous blood samples (heparinized) were taken on admission, six or seven times in the course of the next forty-eight hours, and then daily or every other day for one or more weeks. Such frequent sampling was not always possible since about hálf the children were under four years of age. Samples were taken for preference from an arm vein, but often the arms were burned. The external jugular vein was frequently used, and less often the internal saphenous vein at the ankle. A drawback of the saphenous vein is that in the presence of even a slight degree of vasoconstriction it yields only very small amounts of blood. The site of sampling was in part determined by the distribution of the burns. Because of the risk of introducing infection it was felt unjustifiable to uncover a burned area for the sake of obtaining a blood sample when the information to be derived from this was not essential for treatment.

In the first part of the series red cell counts and haemoglobin and haematocrit estimations were compared; it soon became evident that the red cell counts were unreliable (i.e. they did not follow the curves of the other two) and they were discarded in the later cases. Haemoglobin seemed reliable when done under uniform conditions (i.e. by the same person using a constant source of light) but some degree of hypochromic anaemia is so common among the children in an industrial area that the significance of a level of, say 90 per cent. $(13 \cdot 6 \mathrm{~g}$.) is difficult to assess. The haematocrit value, on the other hand, tends to be much more constant in the child population. It also has the advantage of easy technique, giving a quick and accurate result in a ward laboratory, which is essential when dealing with an acutely ill child in the middle of the night. (The normal values for all three at different ages were taken from the table compiled by Wintrobe (1942) from collected data. Values for normal blood and plasma volumes were taken from the tables given by Brines et al. (1941).)

Thus the haematocrit proved to be the most valuable single criterion of plasma loss, and in the 
later cases it was used exclusively in calculations, although haemoglobin levels were followed in parallel as a check. The amount of plasma loss was calculated as in the following example:

CASE 30. C. R., aged two years :

Normal haematocrit for age $=35$ per cent.

Normal blood volume for age $=750 \mathrm{c.cm}$.

Normal plasma volume for age $=490 \mathrm{c} . \mathrm{cm}$.

Abnormal haematocrit ( $2 \frac{1}{2}$ hours after scalding) $=50$ per cent.

Let abnormal blood volume $=x \mathrm{c.cm}$. Then (if total red-cell volume, $R$., is constant),

$$
\frac{35 \times 750}{100}=\mathrm{R}=\frac{50 \times \mathrm{x}}{100}
$$

Therefore $x=\frac{35 \times 750}{50}=525 \mathrm{c.cm}$.

Therefore amount of plasma lost over $2 \frac{1}{2}$ hours $=750-525 \mathrm{c.cm}$.

$$
=225 \mathrm{c} . \mathrm{cm} \text {. }
$$

Or $\frac{225 \times 100}{490}=45$ per cent. of total plasma volume.

If it is assumed that no marked dilution of the blood by tissue fluid occurs, and the rapidity of the loss from the circulation after this type of injury probably justifies the assumption, not only the actual plasma deficiency at the time of the calculation, but the rate of loss can be estimated in this way. The loss was apparently underestimated in some cases where the time elapsing since the accident was more than five or six hours, which suggests that, later, dilution is a significant factor. In very severe cases there is haemolysis of red cells shown by red colouration of the plasma, and in this type of case the loss would again be slightly underestimated. In spite of these drawbacks, as will be shown later, treatment based on such calculations produced more satisfactory results than that guided solely by clinical criteria.

From the same blood samples estimations of blood urea and blood sulphonamide levels were made in the chemical pathology department of the hospital. In a few cases plasma proteins were also estimated by means of the Van Slyke copper sulphate method.

\section{RESULTS OF OBSERVATIONS}

Early death. Death occurring during the first hour was not observed in this series, but it does not seem likely that it can be due mainly to the effects of fluid loss as these take several hours to become established (vide infra). Probably other factors are at work such as hyperpyrexia, suffocation by fumes, etc., but these cases do not reach hospital alive and are really of preventive rather than therapeutic interest.

The clinical picture may be divided into three successive phases, namely: (1) fluid loss and concentration of the blood; (2) 'toxaemia'; (3) secondary infection and wasting. (The first phase probably includes both the primary and secondary shock referred to by Wilson et al. (1938), and also some of the features characterizing their ' early toxaemia'; as no tannic acid dressings were used in this series the symptoms which they describe associated with liver necrosis were not seen.)

\section{Fluid Loss and Blood Concentration}

The phase of fluid loss and concentration of the blood was studied in detail. It was found that a steady fluid loss persisted for about twenty-four hours, starting immediately or very soon after the injury, and a smaller loss for a further twelve to twenty-four hours; but rate and duration of loss seemed to vary considerably in different patients, other factors being equal. From an analysis of the case records, a composite picture of the physical signs and symptoms of progressive reduction of plasma volume and resulting haemoconcentration was obtained. It is summarized as follows and divided into eight stages in the usual and fairly constant order of appearance:

(1) rising pulse rate;

(2) thirst;

(3) coolness of the nose and extremities and mild restlessness;

(4) pallor, coldness, and cyanosis of the extremities with narrowing of the pulse, commencing drowsiness, and vomiting;

(5) marked restlessness with mental confusion and falling blood pressure;

(6) air hunger;

(7) loss of consciousness;

(8) complete circulatory failure and death.

The later stages were seen only in unresuscitated cases, but from these it appears that death can occur within an hour of the onset of marked restlessness and mental confusion (case 15, M. S.). In small children convulsions may appear at about stage (5) or (6).

Pulse rate. This appeared to be of little value in assessing the severity of the illness during the first forty-eight hours. A steady rise or a steady fall is probably significant of deterioration or improvement, but many children showed gross and irregular fluctuations which bore no obvious relationship to the course of their illness. The rate appeared to be affected by plasma reactions, temperature variations, restlessness, and anaesthesia, as well as by changes in blood concentration.

The width of the peripheral pulse and the ease with which it was felt were of much greater value. As plasma volume decreased the pulse became steadily more difficult to feel until it was impalpable. The ease with which the blood pressure could be measured by the auscultatory method followed closely the width of the pulse. In the later part of the first forty-eight hour period, and after anaesthesia, haemoconcentration was not always accompanied by peripheral vasoconstriction, however, and the fullness of the pulse was then deceptive in judging the patient's condition. 
Cyanosis with pallor and coldness of the skin. These are indicative of peripheral vasoconstriction, and their appearance and persistence were of the greatest import. Their absence did not necessarily mean that all was well, but their appearance in fourteen cases corresponded to a loss of 30 to 50 per cent. of the total plasma volume, as shown by a rise in the haematocrit to between 120 and 150 per cent. of the normal value. Although these signs can occur as a result of exposure to cold, they were, almost without exception in the cases studied, associated with serious fluid loss and it would have been dangerous to disregard them.

The blood pressure. During the first two days the blood pressure showed certain characteristic changes which are of interest and of some help in guiding treatment; but it was clear, and can be stated dogmatically, that to wait for a marked fall in blood pressure before commencing intravenous therapy is to take unnecessary risks. In the majority of the children the blood pressure was maintained at normal levels or above, even when the blood volume was dangerously reduced (see fig. 9, J. P.). Hypotension is thus always significant but usually a late sign.

Hypertension, on the other hand, was seen at this stage in twenty-one out of twenty-seven cases in which readings were available. In the majority it appeared only after plasma or serum administration had been commenced, but in two cases it was present on admission (cases 20 and 28). Table 3 shows the highest level reached in each case and the initial level (usually before intravenous therapy). As the children were at this time quite co-operative and often sleeping, it does not seem as though this hypertension could be attributed solely or even mainly to emotional causes. The whole question of hypertension will be discussed more fully later. Even in severe reduction of plasma volume the diastolic pressure could remain above normal, though the systolic had fallen below normal; the narrowing of the pulse pressure in this way may be as significant as a general fall in tension (fig. 9, J. P.).

The mental state. This followed a very characteristic pattern and was related to the injury rather than to the individual personalities of the children. During the first few hours after burning they showed a striking composure and absence of anxiety; they were alert, co-operative, quiet, and appeared to have little or no pain. They allowed themselves to be examined and pricked with little protest. They usually had no complaints but asked repeatedily for drinks. Their behaviour was in marked contrast to the often hysterical state of their parents.

As the picture advanced and vasoconstriction appeared, they often shivered and complained of the cold although the room was quite warm, and asked incessantly for drinks. If they vomited they appeared unconcerned and asked immediately for another drink. About this stage they tended to become drowsy and to sleep if left alone, but very lightly, and were readily disturbed. Restlessness then appeared and was of a characteristically spasmodic type; it took the form of sudden, heaving movements of limbs and body, struggling against restraint, shouting out, throwing off the bedclothes, etc. The spasms passed off as suddenly as they came on and the child was asleep and limp in a few seconds. Drowsiness and mental confusion accompanied the restlessness.

That restlessness of this type was a manifestation of reduced plasma volume was shown by its rapid and striking relief by efficient intravenous therapy. It is a danger signal of the first order and must never be disregarded. Sedatives given at this stage (notably morphine) may mask the gravity of the situation with adverse effects; moreover they are rarely necessary once the fluid loss has been relieved. Smaller children, and usually those less severely injured, were sometimes fretful and resistant to handling in the early stages because of separation from their mothers, but the restlessness was unaccompanied by the other signs of plasma loss and was not spasmodic in character.

Comparison of haematocrit levels. Comparison of the haematocrit levels with the clinical findings described above showed that the haematocrit was a more sensitive index of fluid loss and was considerably raised befóre clinical illness was obvious. As shown in table 2 , there was a fairly close correlation between the severity of the clinical illness and the amount of fluid loss (estimated as described on page 132).

Stages 1, 2, and 3 corresponded with up to 30 per cent. plasma loss, stages 4 and 5 with 30 to 50 per cent. plasma loss, and stage 8 in one case with 69 per cent. plasma loss.

(Fourteen readings with the clinical picture at stages 1,2 , and 3 showed a plasma loss of 8 per cent. to 33 per cent. of the total, with one at 58 per cent.

Six readings between stages 3 and 4, and five at stage 4 showed losses of 23 per cent. to 47 per cent. of the total, and three readings between stages 4 and 5 showed losses of 46 per cent. to 50 per cent. of the total.)

Before stage 4 is reached the signs are not obvious to the inexperienced eye and have always to be looked for, so that up to 30 per cent. of the total plasma volume can be lost without any anxiety being felt concerning the child's condition. This may be interpreted as indicating either that, because a loss of up to 30 per cent. of the total plasma volume is not associated with obvious clinical deterioration it can be disregarded, or that clinical signs are a rather late manifestation of a progressive state, and that the only safe estimate of the seriousness of the fluid loss is obtained by direct haematological examination. When the rapidity with which the haematocrit can rise in even moderately severe cases is allowed for (fig. 10, E. S.), and when it is realized that death can occur probably at any time after 
60 per cent. to 70 per cent. of the total plasma has been lost, the conclusion that the latter interpretation is the correct one becomes manifest.

Three children died unresuscitated because of the nature and distribution of the local lesions (deep burns covering 60,70 , and 75 per cent. of the body surface) and they all died between six and seven hours after the accident; one of them (case 15, M. S.) showed no marked restlessness or mental confusion until one hour before death. The haematocrit in heart blood obtained immediately after death in case $26, \mathrm{~N}$. B., was 66 per cent.,

TABLE 2

TO SHOW THE RELATIONSHIP OF THE CLINICAL PICTURE TO THE AMOUNT OF PLASMA LOSS

\begin{tabular}{|c|c|c|c|c|c|}
\hline $\begin{array}{l}\text { Case } \\
\text { No. }\end{array}$ & Age & $\begin{array}{c}\text { Hours } \\
\text { after } \\
\text { injury }\end{array}$ & $\begin{array}{l}\text { Stage of } \\
\text { clinical } \\
\text { picture }\end{array}$ & $\begin{array}{c}\text { Plasma } \\
\text { loss } \\
\%\end{array}$ & $\underset{\%}{\text { Range }}$ \\
\hline $\begin{array}{l}10 \\
22 \\
13 \\
20\end{array}$ & $\begin{array}{r}2 \\
7 \\
2 \\
10\end{array}$ & $\begin{array}{l}3 \\
1 \\
6 \\
1 \frac{1}{2}\end{array}$ & $\begin{array}{r}1 \\
\text { and } \\
2\end{array}$ & $\begin{array}{l}22 \\
32 \\
29 \\
34\end{array}$ & \multirow{3}{*}{$\begin{array}{c}8-33 \\
(+1 \text { at } 58)\end{array}$} \\
\hline $\begin{array}{l}12 \\
21 \\
31 \\
19\end{array}$ & $\begin{array}{c}2 \frac{1}{2} \\
5 \\
5 \\
10\end{array}$ & $\begin{array}{c}6 \\
1 \\
1 \frac{1}{2} \\
21^{2}\end{array}$ & $2-3$ & $\begin{array}{r}33 \\
8 \\
22 \\
58\end{array}$ & \\
\hline $\begin{array}{r}8 \\
10 \\
14 \\
18 \\
21 \\
24 \\
\end{array}$ & $\begin{array}{c}2 \\
2 \\
10 \\
9 \\
5 \\
31 \\
\end{array}$ & $\begin{array}{l}3 \\
6 \\
5 \\
2 \\
2 \frac{1}{2} \\
4\end{array}$ & 3 & $\begin{array}{l}26 \\
31 \\
28 \\
22 \\
19 \\
31\end{array}$ & \\
\hline $\begin{array}{r}9 \\
14 \\
20 \\
23 \\
25 \\
29\end{array}$ & $\begin{array}{c}1 \\
10 \\
10 \\
3 \frac{1}{2} \\
2 \frac{3}{4} \\
3\end{array}$ & $\begin{array}{l}3 \frac{1}{2} \\
7 \\
2 \frac{3}{4} \\
2+ \\
4 \\
4\end{array}$ & $3-4$ & $\begin{array}{l}23 \\
44 \\
46 \\
41 \\
29 \\
37\end{array}$ & \multirow{2}{*}{$23-46$} \\
\hline $\begin{array}{r}1 \\
5 \\
6 \\
11 \\
28\end{array}$ & $\begin{array}{l}4 \\
1 \frac{1}{2} \\
8 \\
5 \\
5\end{array}$ & $\begin{array}{c}36 \\
19 \\
4 \\
1+ \\
1 \frac{1}{2}\end{array}$ & 4 & $\begin{array}{l}47 \\
37 \\
41 \\
37 \\
46\end{array}$ & \\
\hline $\begin{array}{l}27 \\
30 \\
16\end{array}$ & $\begin{array}{c}10 \frac{1}{2} \\
2 \\
8\end{array}$ & $\begin{array}{l}2 \\
2 \frac{1}{2} \\
3\end{array}$ & $4-5$ & $\begin{array}{l}50 \\
46 \\
47\end{array}$ & $46-50$ \\
\hline 26 & 3 & $6 \frac{1}{2}$ & 8 & 71 & \\
\hline
\end{tabular}

giving an estimated plasma loss of about 70 per cent. of the total. Case 28, M. W. (fourth and fifth degree burns of trunk and limbs), who survived and did well, lost 46 per cent. of her total plasma in the first one and a half hours, though her clinical state at that time was only just stage (4) and she did not appear seriously ill.
The following case histories are illustrative of the phase of fluid loss:

Case 3. L. D., aged six years, was admitted to hospital three and a half hours after being scalded. The scalds were mainly second and third degree and covered about 15 per cent. of the body surface (Plate IV, fig. 2a and b). They were dressed under a general anaesthetic (open ether) at six hours with tulle gras and a liberal amount of sulphanilamide powder (exact quantity unknown). When first seen at seven hours she was recovering from the anaesthetic, the face and lips were pink, the skin was dry and the exposed parts cool, the nose cold, but the forehead warm. She was not restless. The pulse felt broad and full but the rate was 180 per minute; blood pressure was $100 / 70 \mathrm{~mm}$. Hg. Respirations were 22 per minute, deep and occasionally sighing. The haemoglobin was $17 \cdot 5 \mathrm{~g}$. (photoelectric method) compared with an expected value of $12.5 \mathrm{~g}$.

Eight hours after the accident she was making restless movements of her arms and legs, though still sleeping, and she sighed deeply if disturbed. Her cheeks and lips were slightly cyanosed but her nose was warm. Pulse, respirations, and blood pressure were unchanged. Two and a half hours later she was lying asleep. Breathing was deep and sighing. The nose and exposed arm and hand were cold, and the lips and cheeks were cyanosed. The pulse was impalpable at the wrist, and the blood pressure uncertain because of the faintness of the sounds. The tongue was dry. The pupils were widely dilated but reacted to light. She awoke and appeared dazed, but spoke rationally. During the next thirty minutes she began to turn restlessly in her sleep and to throw off the bedclothes.

Eleven hours after the accident, after a drink of glucose, she vomited coffee-ground material; this was red at first but turned dark brown later and gave a positive Guaiac test. Three-quarters of an hour later the blood pressure was $85 / 50 \mathrm{~mm}$. $\mathrm{Hg}$., and the pulse $130 ; 200 \mathrm{c.cm}$. of plasma were given into an arm vein in twenty minutes; after this she was quieter but still cold and cyanosed. She then became markedly restless, turning right over on to her face with sudden powerful heaving movements, but between the spasms she lay quietly. During a spasm the transfusion needle was displaced from the vein.

At the thirteenth hour the left internal saphenous vein was canalized and $150 \mathrm{c.cm}$. of plasma were given in thirty minutes, but her nose remained cold and her cheeks cyanosed. The blood pressure was $90 / 70 \mathrm{~mm}$. Hg. Half an hour later she kicked the canula out of the vein; she was then so restless that it took two people to keep her in bed, and it was almost impossible to hold the leg still. She was very cold and cyanosed and seemed quite unconscious of her struggling. The blood pressure was $90 / 65 \mathrm{~mm}$. Hg. After some delay the canula was reinserted and the flow started with a two-way syringe. 
Fourteen and a half hours after the accident, after having received $500-600$ c.cm. plasma (given mostly by two-way syringe because of marked venespasm) she was less cyanosed, the blood pressure was 105/70 and the pulse 120 . At the fifteenth hour, after $1,000 \mathrm{c.cm}$. of plasma had been given, she was sleeping quietly and had had no further restless spasms; her cheeks and lips were pink, and the pulse easy to feel (rate 110). The blood pressure was $110 / 70$ (sounds heard easily). Her nose and exposed hand were still cold, but the respirations were easier and less deep. When awakened she appeared rational and to be taking notice for the first time for several hours. Sixteen and a quarter hours after the accident she was sleeping quietly, but she had been-awake and talking sensibly. Her face was flushed and pink, and extremities warm (though her nose was still cool); the pulse was 120 and the blood pressure 130/85. The restlessness had quite gone although no sedative had been given.

Case 5. R. A., aged one and a half years, was admitted with scalds involving about 10 per cent. of the body surface. They were cleansed and dressed under a general anaesthetic at 8.30 p.m. three and a half hours after the accident. He was very restless during the night until given $5 \mathrm{gr}$. potassium bromide and chloral, when he became very quiet with cold extremities and nose, and was noticed to be cyanosed.

When first seen eighteen hours after the injury he was pallid and cyanosed and his eyes a little sunken. He was sleeping, but awoke when disturbed and cried loudly. His extremities were cold in spite of hot bottles in the bed. He took a small drink but vomited immediately. The blood pressure was $100 / 65$. The haematocrit was 46 per cent. (normal for age, 35 per cent.). At the twentieth hour an attempt to set up an intravenous drip was unsuccessful. An hour and a half later he was very cyanosed and restless in spasms, and very cold. He did not appear conscious, but resisted interference. He stared, and did not blink at a light. The drip was started with a two-way tap, and after 50-60 c.cm. it ran well. He then had several "turns" when his eyes turned up into the corners and the right arm was held stiffly and shaken backwards and forwards. His teeth were clenched and unclenched. He was taking no notice and breathing very noisily, and the whole picture suggested a fit.

By the twenty-fourth hour, after $300 \mathrm{c.cm}$. of serum, he was greatly improved. He was lying fairly quietly with his eyes closed. The cyanosis had practically gone; the face was still pale but the lips more pink. He felt warm all over and his tongue was moist. The haematocrit had fallen to 32 per cent. By the twenty-seventh hour, after $450 \mathrm{c.cm}$. of serum, he was warm and flushed and quite rational. The blood pressure was $100 / 60$. The pulse had risen to 180 and respirations to 60 . The temperature was $99^{\circ} \mathrm{F}$. He made a good recovery.
Case 15 . M. S., aged five years, had 60 per cent. of her body surface affected by fourth- and fifthdegree burns when her clothing was completely burned off her. She was not resuscitated. On admission three and a half hours later she lay quietly in bed as though nothing had happened, showed no fear or apprehension, and appeared to have no pain at all. She was quite alert, answered questions, and allowed herself to be turned over and examined without protest. The distribution of the lesions was as shown in the photograph (Plate IV, fig. 3 a and b) and over the major part the skin was completely coagulated, dark brown, dry and leathery, and insensitive to pricks. Beneath the skin there was obvious swelling due to exudation, especially marked over the chest and upper abdominal wall. A band of bright red third-degree burn at the edge was oozing freely. She kept asking for drinks which were vomited immediately. Her extremities were cold and cyanosed, her radial pulse impalpable, and the blood pressure unmeasurable, the latter probably because of the extensive exudation beneath the coagulated skin, the whole arm feeling stiff and rubbery with the tension. The heart sounds were clearly audible over the precordium, and the rate was 120-130. Mouth temperature was $96^{\circ} \mathrm{F}$. Only $0.5 \mathrm{c} . \mathrm{cm}$. of blood could be obtained from puncture of the internal saphenous vein at the ankle; then the vein collapsed and could not be refilled. There was haemolysis (plasma red) but the calculated haematocrit was 48 per cent. (Van Slyke sp. gr. method.)

By five hours after injury she was drowsy and becoming unco-operative, but could be roused. Thirst was intense and she vomited everything. She was very cold and cyanosed, her heart sounds were only audible directly over the sternum, her breathing was deep and laboured, and she gasped when talking. The optic fundi showed gross engorgement of the veins with dark blood; the arteries were still red but very narrow. She then became suddenly restless, moving up the bed and from side to side with considerable strength, then for a few moments lying still, apparently unconscious with eyes closed and deep respirations, then waking up again to demand a drink, trying to get out of bed, complaining of the cold, and so on. She was cold all over and extremely cyanosed, with laboured respirations and marked air hunger. Even at this stage the dominant feature was thirst. She was given morphia, gr. 1/8, and rapidly became quiet and unconscious. She died six and a half hours after the accident.

\section{The Phase of 'Toxaemia'}

This phase is less well defined and established; it is made up of a group of signs which were related in time and frequency of occurrence, and may be related aetiologically. They were first seen towards the end of the first twenty-four hours after burning, and lasted for varying periods up to six or eight weeks. They did not seem to be attributable either 
to fluid loss or to secondary infection, and indeed their rapid appearance and their gradual slow disappearance suggested the action of some chemical 'toxin'. They were seen only in certain cases, usually severe (burns and scalds), but some of the worst cases did not show them. They are : (a) sustained pyrexia; (b) increased depth and rate of respiration; (c) moderate, sustained hypertension; (d) drowsiness and signs of increased intracranial tension, with or without convulsions.

Pyrexia and respiration rate. The first two (a) and (b) were usually associated and it is possible that the hyperventilation was a direct effect of the pyrexia. The temperature showed a characteristic pattern, rising steeply to reach $103^{\circ}$ to $105^{\circ} \mathrm{F}$. at the end of the first twenty-four hours, then falling very slowly to normal over a period of weeks. During this time a moderate swing within a range of $2-3^{\circ} \mathrm{F}$. was present, but the general curve was remarkably steady. It differed from the pyrexia of secondary infection by the absence of marked irregular fluctuations and by its much earlier onset. Fig. 11, C. R., shows its character well. The phenomenon was seen in twelve cases to a varying degree (numbers $5,7,10,16,18,21,22,23,24,25$, 27, 28, and 30). They were all severe, ten burns and three scalds, but the latter showed considerable sloughing. In eight cases the pyrexia was associated with hyperterision.

Hypertension. Hypertension (c) during plasma or serum administration was seen in twenty-two cases out of twenty-seven where readings were obtained. In fourteen of these, and in one case where no intravenous fluid was given, the hypertension was continued for varying periods up to several weeks after the resuscitation period. The height in each case is shown in table 3. As has already been stated, great care was taken to obtain readings at rest, and if the child was unco-operative readings were discarded. For this reason the duration of the hypertension in most of the cases is not known. During the third and fourth weeks the children became so afraid of being handled that the investigation had to be given up. Fig. 12, C. R., shows a typical course so far as it could be followed. Although the hypertension was most marked in cases where there was much sloughing, it was not an essential accompaniment of sloughing, nor did it subside as soon as the sloughs had separated. Its occurrence was not directly associated with depth and severity of lesion, for it was quite absent in cases 9,10 , and 12 (all 20 per cent. in extent) and confined to the resuscitation period in cases $11,18,29$, and 31 (among which were one 20 per cent. and one 25 per cent. deep burn).

It seemed that there were at least three factors in the production of hypertension, reaction to plasma or serum given intravenously (this varying with the rate of administration), some unknown mechanism co-existing with sloughing of dead tissue but outlasting it, and an individual (presumably constitutional) liability. The latter was very definite and raises the interesting possibility of a connexion with the essential hypertension of adult life.

Drowsiness. The fourth - manifestation (d), namely drowsiness and signs of increased intracranial pressure, was present in six cases (numbers 6 , $7,16,20,22$, and 27). All these showed the typical sustained pyrexia and all showed hypertension in the resuscitation period and later if they survived (with the exception of case 7 , in which no readings were obtained: which is unfortunate as the picture in this case was very striking). They were all very severe cases, five deep burns and one bad scald, and all received intravenous plasma or serum.

The onset of the cerebral signs was fairly sudden, with loss of consciousness occurring between nineteen and thirty-three hours from the accident, but preceded by drowsiness and a tendency to sleep for several hours. Periods of apparent coma, with stertorous breathing and lack of response to painful stimuli, alternated with lucid intervals or restless delirium; the depth of unconsciousness often showed marked and rapid fluctuations. Muscular rigidity and twitchings were seen, and in two cases epileptic convulsions. Cerebral oedema was considered to be the probable explanation of these phenomena. Lumbar puncture in two cases showed a high cerebrospinal fluid pressure $(250 \mathrm{~mm}$. and $360 \mathrm{~mm}$. + of cerebrospinal fluid) and in cases 6 and 20 (dying after five days and twenty-two hours respectively) necropsy revealed evidence of oedema of the brain; it was also seen at necropsy in cases 15 and 17, who died at six or seven hours without resuscitation. It is noteworthy that at the time of onset of the nervous symptoms all the cases showed a haematocrit value still above normal, and three showed clinical signs of reduced plasma volume; it does not seem likely, therefore, that the oedema could be attributed to overadministration of intravenous fluid. On the contrary its occurrence in cases where the circulation was unsatisfactory suggests that cerebral anoxia from undertransfusion may possibly be a factor in causation.

The duration of these nervous signs was usually only two or three days, and in no case exceeded ten days, thus differing from the pyrexia and hypertension.

Summaries of case histories illustrating the nervous phenomena are given below, and case 7 is described more fully.

Case 6. C. N., aged eight years, had 60 per cent. deep burns. This girl showed marked concentration of the blood on admission four hours after burning, but responded to intravenous therapy and after twelve hours was alert, rational, and co-operative. She became rather drowsy during the next twelve hours, then suddenly restless and irrational at the twenty-third hour. She was mentally confused and incontinent of urine during 
TABLE 3

HYPERTENSION DURING AND AFTER INTRAVENOUS THERAPY, AND ITS RELATIONSHIP TO TYPE OF LESION AND TO CEREBRAL SIGNS AND PYREXIA

\begin{tabular}{|c|c|c|c|c|c|c|c|}
\hline $\begin{array}{l}\text { Case } \\
\text { No. }\end{array}$ & $\begin{array}{l}\text { Burn } \\
\text { or } \\
\text { Scald }\end{array}$ & $\begin{array}{l}\% \text { body } \\
\text { surface } \\
\text { involved }\end{array}$ & $\begin{array}{c}\text { Range of B.P. } \\
\text { during } \\
\text { intravenous therapy }\end{array}$ & $\begin{array}{l}\text { Days after } \\
\text { end of } \\
\text { i.v. therapy }\end{array}$ & B.P. & $\begin{array}{l}\text { Cerebral } \\
\text { signs }\end{array}$ & $\begin{array}{c}\text { Sustained } \\
\text { pyrexia }\end{array}$ \\
\hline 1 & $\mathbf{S}$ & 15 & $110 / 75-180 / 115$ & $2^{\frac{1}{2}}$ & $\begin{array}{l}145 / 105 \\
130 / 85\end{array}$ & & \\
\hline 2 & $\mathbf{S}$ & 6 & No. I.V. Therapy & 7 & $125 / 85$ & & \\
\hline 3 & $\mathbf{S}$ & 15 & $85 / 50-130 / 85$ & 18 & $\begin{array}{l}130 / 95 \\
130 / 95\end{array}$ & & \\
\hline 4 & $\mathbf{S}$ & 5 & No Hypertension & \multicolumn{2}{|c|}{ No Hypertension } & & \\
\hline 5 & $\mathbf{S}$ & 12 & $90 / 50-120 / 65$ & \multicolumn{2}{|c|}{ No Hypertension } & & \\
\hline 6 & B & 60 & $100 / 75-140 / 95$ & \multicolumn{2}{|c|}{ No Hypertension } & ++ & ++ \\
\hline 8 & $\mathbf{S}$ & 10 & $105 / 70-120 / 75$ & 5 & $115 / 60$ & & \\
\hline 9 & $\mathbf{S}$ & 20 & No Hypertension & \multicolumn{2}{|c|}{ No Hypertension } & & , \\
\hline 10 & $\mathbf{S}$ & 20 & No . Hypertension & \multicolumn{2}{|c|}{ No Hypertension } & & + \\
\hline 11 & B & 20 & $100 / 60-140 / 75$ & \multicolumn{2}{|c|}{ No Hypertension } & $\cdot$ & \\
\hline 12 & B & 20 & No Hypertension & \multicolumn{2}{|c|}{ No Hypertension } & & \\
\hline 13 & $\mathbf{S}$ & 20 & $110 / 55-145 / 100$ & \multicolumn{2}{|l|}{ No Readings } & & \\
\hline 14 & B & 30 & $75 / 50-120 / 80$ & 3 & $125 / 80$ & & \\
\hline 16 & B & 40 & $70 / 55-160 / 125$ & $\begin{array}{r}2 \\
13 \\
42 \\
\end{array}$ & $\begin{array}{l}140 / 70 \\
175 / 85 \\
135 / 95 \\
\end{array}$ & +++ & ++ \\
\hline 18 & B & 12 & $120 / 80-135 / 90$ & \multicolumn{2}{|c|}{ No Hypertension } & & + \\
\hline 19 & B & 7 & $88 / 65-120 / 80$ & 11 & $115 / 80$ & & \\
\hline 20 & B & 50 & $145 / 110-110 / 85$ & \multicolumn{2}{|l|}{ Died } & $+t+$ & \\
\hline 21 & B & 15 & $\begin{array}{c}115 / 60-135 / 100 \\
\text { । }\end{array}$ & $\begin{array}{r}3 \\
10 \\
\end{array}$ & $\begin{array}{l}135 / 80 \\
105 / 70 \\
\end{array}$ & & + \\
\hline *22. & B & 30 & $160 / 105-190 / 106$ & $\begin{array}{r}2 \\
12 \\
28\end{array}$ & $\begin{array}{l}140 / 100 \\
150 / 85 \\
150 / 95\end{array}$ & ++ & ++ \\
\hline 23 & B & 30 & $90 / 65-140 / 80$ & $\begin{array}{r}2 \\
18\end{array}$ & $\begin{array}{l}130 / 65 \\
135 / 75\end{array}$ & & + \\
\hline 24 & $\mathbf{S}$ & 12 & $90 / 64-130 / 80$ & \multicolumn{2}{|l|}{ No Readings } & & \\
\hline 25 & $\mathbf{S}$ & 20 & $110 / 40-140 / 90$ & 6 & $125 / 75$ & & $(+)$ \\
\hline 27 & B & 40 & $\begin{array}{r}\text { Unobtainable-_- } \\
150 / 100\end{array}$ & $\begin{array}{r}2 \\
5 \\
11 \\
28 \\
42\end{array}$ & $\begin{array}{l}120 / 75 \\
150 / 85 \\
135 / 95 \\
130 / 110 \\
135 / 95\end{array}$ & ++ & \\
\hline 28 & B & 35 & $110 / 85-135 / 85$ & $\begin{array}{r}1 \\
21 \\
42\end{array}$ & $\begin{array}{l}135 / 95 \\
135 / 105 \\
130 / 95\end{array}$ & & + \\
\hline 29 & $\mathbf{S}$ & 15 & No Hypertension & \multicolumn{2}{|c|}{ No Hypertension } & & ++ \\
\hline 30 & $\mathbf{S}$ & 30 & $115 / 65-135 / 95$ & $\begin{array}{r}2 \\
3 \\
14 \\
\end{array}$ & $\begin{array}{l}130 / 85 \\
160 / 100 \\
130 / 80\end{array}$ & & \\
\hline 31 & B & 25 & $105 / 70-115 / 80$ & 11 & $\begin{array}{r}115 / 75 \\
95 / 55 \\
\end{array}$ & & \\
\hline
\end{tabular}


the night, but at the forty-second hour was rational and quiet. Forty-six hours after injury she had a sudden screaming attack, throwing her arms and legs about and breathing deeply. Thereafter she became progressively more unreasonable and eventually comatose. She developed bronchopneumonia and died on the fifth day.

Case 16. M. H., aged eight years, had 40 per cent. deep burns and showed marked haemoconcentration which was controlled with difficulty. She remained mentally clear, but dozed frequently during the first twenty-four hours. Her breathing then became noisy, and by the twenty-fifth hour she was comatose, unrousable, and her mouth twitching. Lumbar puncture two and a half hours later showed a cerebrospinal fluid pressure of $250 \mathrm{~mm}$. After 10 c.cm. of cerebrospinal fluid were removed slowly she roused and spoke a few words. Periods of coma with lucid intervals continued. Two and a half days after the accident she was normally conscious and alert. She died at six weeks from secondary infection and septic bronchopneumonia.

Case 20. J. P., aged ten years, had 50 per cent. deep burns, and moderate plasma loss on admission one and a half hours after injury, but the haematocrit rose steeply during the next hour. His blood pressure was $145 / 100 \mathrm{~mm}$. $\mathrm{Hg}$. before intravenous therapy. Resuscitation with intravenous plasma and saline was started and was maintained until death, but he was given insufficient quantities of fluid and his circulation was unsatisfactory for many hours before he died (fig. 9). He became drowsy and difficult to rouse, but when awake he was rational and asking for drinks. At the nineteenth hour he suddenly took a convulsion which lasted for five minutes; he recovered consciousness again but his respirations were deep and heavy. Three and a half hours later he was again mentally confused and resistant to handling and appeared about to take another convulsion. Lumbar puncture showed a pressure of $360 \mathrm{~mm}$. of cerebrospinal fluid ; between 6 and $7 \mathrm{c.cm}$. were removed slowly. Breathing ceased suddenly, was restarted again with artificial respiration, then ceased again, and he died twenty-three hours after his injury. At necropsy the brain showed a well marked pressure cone.

Case 22. C. S., aged seven years, had 30 per cent. deep burns. Intravenous therapy was started early but the haemoconcentration was only partially relieved and she was restless with a rapid pulse all night. After twenty-three hours she became semiconscious, struggling when touched and having restless spasms. She remained drowsy, irrational, and unco-operative for a further twenty-four hours, then quickly recovered normal mental clarity. She subsequently made a good recovery.

Case 27. S. C., aged ten and a half years, had 40 per cent. deep burns. The blood showed marked concentration on admission one and a half hours after injury. She was given intravenous plasma, but the amount was inadequate and the haematocrit remained well above normal (fig. 15) but she was alert, quiet, and co-operative. At the twenty-eighth hour she complained of feeling unwell, wanted to lie down, and her temperature rose to $104^{\circ} \mathrm{F}$. An hour later she suddenly became quite unconscious and unrousable and was breathing deeply. Her pupils were very small. Fifteen minutes later she was rousable but very drowsy and complaining of headache. For some hours she remained very drowsy with alternating rational and irrational responses, but she was never comatose. She was mentally clear by forty-eight hours and then improved steadily; however, she died with wasting and bronchopneumonia after eight weeks.

Case 7. A. B., aged one and three-quarters years, suffered 30 per cent. third-degree scalds. He was admitted at one and a half hours later and already showed coldness and cyanosis of the extremities and facial pallor. He was excited and restless and screamed when touched. There was an estimated loss of 30 per cent. of plasma volume. An intravenous drip was commenced one hour after admission, and $100 \mathrm{c.cm}$. serum were given quickly; after $200 \mathrm{c} . \mathrm{cm}$. he became quiet and fell asleep, and after $350 \mathrm{c.cm}$. (at four hours) the vasoconstriction had gone. At twelve hours he was quiet, alert, and warm, but cyanosed, and the estimated plasma deficiency was still 30 per cent. of the total (after $700 \mathrm{c.cm}$. serum intravenously, equivalent to 120 per cent. of normal plasma volume). By fourteen and a half hours he was restless and delirious with marked cyanosis, though his skin was warm and his temperature was $104^{\circ} \mathrm{F}$. He slept a good deal. At twenty-two hours he took a convulsion with tonic and clonic spasms. Shortly after this his blood showed some concentration but less than at twelve hours. His blood pressure was unobtainable because both arms were affected. After the convulsion he became comatose but his lips were pink. The right pupil was dilated and inactive, the left one small. There was intermittent tonic spasm of the left leg and the left plantar response was extensor. There was no neck stiffness. Twenty-five and a half hours after injury he was still comatose; he was relaxed most of the time but had short attacks in which he went stiff and shook all over. Both pupils were large and inactive. The pulse rate had fallen to 110 but the temperature remained $102^{\circ} \mathrm{F}$.

He took a second convulsion at the twenty-eighth hour. Two hours later he was quite comatose, with flaccid muscles and absent reflexes. Both pupils were dilated and inactive, and the respirations had become slow and irregular (16-20 per minute). His face was pallid, and there was slight cyanosis but the skin was hot and sweating. He appeared very ill and likely to die. The depth and frequency of respiration improved with carbon dioxide and oxygen inhalations and the cyanosis was relieved. He 
remained comatose and flaccid with absent reflexes, but respirations rose to 45 and the pulse to 160 , and his face became flushed and pink. The drip was discontinued at thirty hours because of suspected cerebral oedema. An hour later he showed rhythmic twitchings of the right hand, the arm being held stiffly extended. Still an hour later he was improved; the respirations were quiet (rate 50 per minute), the temperature $103^{\circ} \mathrm{F}$., and the pulse 160 . There was no peripheral vasoconstriction. The limbs remained flaccid. The left pupil was small, the right dilated.

At thirty-three hours the unconsciousness was less deep and he was restless with noisy and rapid respirations, and making slow athetoid movements of the limbs. The left plantar response was extensor. He made no response to stimuli. He was first noticed to respond at thirty-nine hours, when he cried out when pricked and resented being handled. The haemoglobin was normal, and the blood urea $68 \mathrm{mg}$. per cent. (He had passed only $120 \mathrm{c.cm}$. of urine in seventeen hours.)

Forty-six and a half hours after injury he opened his eyes in response to stimuli but would not speak. The pupils were inactive, the left knee jerk active and the right absent, and both plantars extensor. He remained in this semi-conscious state, not recognizing his parents but able to drink, for a further twelve hours. His skin was warm and dry; the cyanosis had gone; the temperature was $102^{\circ} \mathrm{F}$. and the pulse 160 .

After two and a half days he was conscious and resenting pricks. Both knee jerks were equal and active and both plantars flexor. The pupils reacted to light but the left remained larger. Haemoglobin was $10 \mathrm{~g}$., temperature $102^{\circ} \mathrm{F}$., and pulse 160 . He was drinking well but passing very little urine. Two hours later he was again drowsy and taking no notice and the left plantar was extensor.

Next day he was conscious and talking, but very irritable. Both plantars were flexor, the left knee jerk ++ and right + . His temperature remained $102^{\circ}$ to $103^{\circ} \mathrm{F}$. On the fourth day he became very quiet again and was not drinking well. His face was flushed and he was found staring with noisy breathing, saliva dribbling from his mouth and rhythmic twitchings of his left face, hand, and arm. The legs were still, but the left knee jerk was increased and the left plantar extensor. The twitchings ceased after five minutes, and three hours later he was drinking again. Four and a half days from his injury he was drowsy and lay very still, but he was conscious and answered simple questions, and there was no spasticity of the limbs. He remained very apathetic and had a slow reaction time for another ten days or so, but ultimately made a very good recovery in four and a half weeks.

\section{Phase of Secondary Infection and Wasting}

Wasting and secondary infection were of marked importance only in lesions covering over 20 per cent. of the body surface, but in these cases they remained an ever-present problem. In this series bacterial infection usually became troublesome about the end of the second or third week and the B. pyocyaneus was a frequent offender. However, even under these conditions healing and skin grafting were not retarded, and it was difficult to know how much of the wasting should be attributed to bacterial infection, and how much to loss of 'purulent' material from a large granulating area.

The wasting, which tended to affect muscles even more than subcutaneous fat, was rapidly progressive in the severe cases, tending to become stabilized after four or five weeks but making no appreciable improvement until healing was well advanced. A proportion of the wasting can be attributed to the aversion from solid food shown during the first two or three weeks; during this period most of the children drank excessively, but unless they would take milk their calorie intake was very low. Later they usually ate very well and attained a high calorie intake for their age. If for any reason their morale failed, the appetite became very poor, and this was at any time an ill omen. It was noticed that appetite was often strikingly improved overnight by correction of anaemia with blood transfusion.

Anaemia of progressive character was seen in all severe cases, even where obvious secondary infection was not present. It was routinely corrected with blood transfusion. The most noticeable effect of anaemia appeared to be a lowering of morale, and of transfusion a raising of morale. The whole question of morale, which is probably the crux of the matter so far as management of this stage is concerned, can conveniently be considered here. As mentioned above, during the first two or three days it was very good. The children were co-operative, talkative, and cheerful. They did not voluntarily move about the bed but they did not mind being lifted, and they seemed to have little pain. It was, therefore, disheartening to find on the third or fourth day that they appeared to feel ill and to have much more pain and discomfort. From then on they became introverted and their illness was their primary concern and interest. They hated to be touched or moved, and cried whenever the bedclothes were taken down. Almost without exception in the bad cases, bedwetting commenced and became intractable-because they wished to avoid being lifted on and off the bedpan. Many of them became extremely quiet and would not answer when spoken to, often pretending to be asleep so that they would not be disturbed. Even among the older children, who would talk and smile quite naturally when undisturbed, fear of being moved was very obvious. Several small children used to howl continuously so long as they were uncovered but would stop immediately and become quite talkative when the bedclothes were put back. The tougher type of child took refuge in bad temper and negativism. One three-year-old boy used to answer every question and remark for many weeks with a surly ' no.' He threw toys and books 
offered to him on to the floor, and hit out viciously at anyone who came near him. He made an exception, however, over food and always received meekly and quietly the nurse who came to feed him. When he had had enough, he pushed her away roughly and shouted 'no.' When he recovered he was a lively and good natured child.

In the early weeks the children usually slept a good deal, but lightly, and were readily awakened by noise or movement. They' dreamed and started in their sleep, often waking up screaming. One little girl woke up regularly crying out, 'Nurse, Nurse, put out the fire, quick.'

Enough has been said to indicate the profound emotional upset which accompanies the physical illness, and the constant care which is required to ensure recovery. In more than one instance commencing dressings without anaesthesia caused an acute failure of morale with loss of appetite and rapid increase in wasting.

(The treatment of this phase will be dealt with later, see page 143.)

\section{Miscellaneous Data}

Blood urea levels. . These were followed constantly for the first few weeks, and in some cases for several months. The highest level in any case was $80 \mathrm{mg}$. per $100 \mathrm{c.cm}$., and increases were usually associated with inadequate fluid intake during the first fortyeight hours, or later with wasting. No case of death in uraemia occurred. Table 4 shows the highest levels reached in all cases.

Blood sulphonamide levels. These were followed in about half the cases. At first sulphanilamide and later sulphathiazole powder was used as a local application on the dressings. Generally speaking they were absorbed rapidly and freely during the first two days, and thereafter to a much smaller extent, i.e. absorption was high during the period of fluid loss. Before this was fully appreciated some high levels were obtained; notably in case 3 it reached $20 \mathrm{mg}$. per $100 \mathrm{ml}$. of blood within two hours of dressing and was still $18 \mathrm{mg}$. per $100 \mathrm{ml}$. fourteen hours later. This child vomited excessively and later had a small haematemesis. In case 5 the level was $26 \mathrm{mg}$. per $100 \mathrm{ml}$. fifteen hours after the first dressing. However, as soon as reasonable care was taken in the use of the powder no further trouble was experienced; only two readings above $8 \mathrm{mg}$. were obtained, and the average was below 4 or $5 \mathrm{mg}$. per $100 \mathrm{ml}$.

The Leucocyte count. This was followed in fourteen cases. Table 5 shows the highest count on the first, second, and third days. The peak was reached usually within the first twelve-hours. Thereafter there was a steady decline to about 8,000 to 10,000 after four or five days. Subsequent rises were found to correspond with secondary infection, but it seemed evident that the initial rise was a response to injury. In case 3 differential counts were done and showed a neutrophil response of 75 to 85 per cent., with a shift to the left most. marked on the second day.

\section{TABLE 4}

BLOOD UREA LEVELS IN TWENTY-SEVEN CASES, SHOWING THE HIGHEST LEVEL

DURING THE FIRST FORTY-EIGHT HOURS, AND SUBSEQUENTLY

\begin{tabular}{|c|c|c|c|c|}
\hline \multirow[b]{2}{*}{$\begin{array}{l}\text { Case } \\
\text { No. }\end{array}$} & \multirow{2}{*}{$\begin{array}{l}\text { Number } \\
\text { of } \\
\text { samples }\end{array}$} & \multirow{2}{*}{$\begin{array}{c}\text { Period } \\
\text { of } \\
\text { days }\end{array}$} & \multicolumn{2}{|c|}{$\begin{array}{l}\text { Highest } \\
\text { blood urea }\end{array}$} \\
\hline & & & $\begin{array}{l}\text { in first } \\
48 \text { hours }\end{array}$ & $\begin{array}{l}\text { after first } \\
48 \text { hours }\end{array}$ \\
\hline 1 & 4 & 7 & 61 & 45 \\
\hline 2 & 3 & 5 & & 32 \\
\hline 3 & 7 & 10 & 34 & 36 \\
\hline 4 & 4 & 7 & 23 & 21 \\
\hline 5 & 7 & 28 & 52 & 32 \\
\hline 6 & 15 & 6 & 29 & 54 \\
\hline 7 & 10 & 10 & 68 & 50 \\
\hline 8 & 10 & 10 & 32 & 29 \\
\hline 9 & 5 & 8 & 36 & 50 \\
\hline 10 & 6 & 12 & 48 & 37 \\
\hline 11 & 9 & 14 & 32 & 29 \\
\hline 12 & 12 & 26 & 35 & 36 \\
\hline 13 & 3 & 6 & 52 & 32 \\
\hline 14 & 13 & 38 & 80 & 45 \\
\hline 16 & 14 & 6 & 60 & 76 \\
\hline 18 & 9 & 7 & 29 & 30 \\
\hline 19 & 7 & 19 & 50 & 40 \\
\hline 21 & 10 & 19 & 39 & 38 \\
\hline 22 & 14 & 50 & 56 & 48 \\
\hline 23 & 12 & 56 & 70 & 48 \\
\hline 24 & 8 & 10 & 47 & 42 \\
\hline 25 & 4 & 4 & 48 & -35 \\
\hline 27 & 19 & 56 & 40 & 50 \\
\hline 28 & 15 & 56 & 64 & 60 \\
\hline 29 & 9 & 35 & 58 & 38 \\
\hline 30 & 12 & 42. & 56 & 38 \\
\hline 31 & 12 & 27 & 43 & 39 \\
\hline
\end{tabular}


TABLE 5

LEUCOCYTE COUNTS DURING FIRST THREE DAYS IN FOURTEEN CASES

\begin{tabular}{c|c|c|c|c}
\hline $\begin{array}{c}\text { Case } \\
\text { No. }\end{array}$ & $\begin{array}{c}\text { First } \\
24 \text { hours }\end{array}$ & $\begin{array}{c}\text { Second } \\
24 \text { hours }\end{array}$ & $\begin{array}{c}\text { Third } \\
24 \text { hours }\end{array}$ & $\begin{array}{c}\text { Extent of } \\
\text { lesion } \\
\%\end{array}$ \\
\hline 3 & 60,000 & 27,000 & 19,000 & 15 \\
\hline 4 & 27,000 & 17,000 & & 5 \\
\hline 5 & 25,000 & 10,000 & 11,000 & 12 \\
\hline 6 & 52,000 & 10,000 & 7,000 & 60 \\
\hline 8 & 44,000 & 23,000 & 22,000 & 10 \\
\hline 9 & 14,000 & 15,000 & 19,000 & 20 \\
\hline 12 & 11,000 & 24,000 & 10,000 & 20 \\
\hline 13 & 38,000 & 25,000 & & 20 \\
\hline 14 & 26,000 & 16,000 & 14,000 & 30 \\
\hline 23 & 36,000 & 22,000 & 17,000 & 30 \\
\hline 25 & 37,000 & 13,000 & & 20 \\
\hline 27 & 38,000 & 28,000 & 24,000 & 40 \\
\hline 28 & 21,000 & 17,000 & 13,000 & 35 \\
\hline 29 & 36,000 & 18,000 & 25,000 & 15 \\
\hline
\end{tabular}

Haematemesis. This was seen in cases 1 and 3 . In case 1 it was associated with cyanosis and convulsions and untreated plasma loss, and in case 3 with vomiting possibly due to a high blood sulphonamide level. It was of mild degree, and the material was either black when vomited or turned so on standing.

Severe melaena with epigastric pain and sudden fall in haemoglobin from 83 to 55 per cent. was seen in case 27 on the fifth day. The epigastric pain continued for several days, but the melaena did not recur; the pain was relieved by alkalis and milk. This child died of wasting and bronchopneumonia after ten weeks, but the autopsy showed no evidence of gastric or duodenal ulceration.

Fluid intake and output. This was found difficult to measure because of unknown loss in the dressings and frequent bedwetting, and occasionally because of vomiting. Thirst was marked during the presence of haemoconcentration, but vomiting was often marked in this period, and in several cases the vomit was equal to the intake by mouth for the first forty-eight hours. In the later stages thirst was usually associated with high temperature, sweating, etc., and was otherwise not excessive. Where the urine output could be measured it was roughly half the total intake by mouth after the first three days. Before that it was governed by the efficiency of intravenous therapy in restoring fluid lost from the burned area.

Examination of the urine. In most cases this showed nothing apart from a mild and transient albuminuria for a day or two. One child had a focal nephritis associated with wound sepsis which cleared up rapidly with penicillin, and another had haematuria after three months in bed and was found to have renal calculi, presumably due to stasis. However, in case 16 (deep burns 60 per cent.) the first urine passed, at twelve hours, was a dark red-brown colour, with a granular brown sediment (reaction acid, specific gravity 1020); albumin +++ ; Guaiac test strongly positive. Microscopically there were no red cells but many granular casts and much granular debris, presumably haemoglobin pigment being excreted by the kidney after intravascular haemolysis. The plasma of the early blood samples in this case was pink-tinged.

Convulsions. These were seen in five cases. It appears that they may be symptomatic of circulatory inefficiency and anoxaemia from untreated haemoconcentration (cases 1 and 5), or of hypertension from plasma reaction (case 13), or of the cerebral disturbance found in the 'toxic' phase (cases 7 and 20). The first type were seen frequently before the days of efficient resuscitation, but can certainly be avoided by proper treatment. In the second instance the hypertension was apparently precipitated by $a$ too rapid administration of intravenous serum for the relief of marked plasma loss (fig. 14, L. K.). This will be mentioned again later (see page 148), but it was due to bad technique and could have been avoided.

The third type has already been discussed and must be regarded as symptomatic of the cerebral disturbance described above. Administration of oxygen or oxygen-carbon dioxide ( 95 to 5 per cent.) mixture was of value, and it may be advisable to transfuse enough plasma or serum to restore the haematocrit to the normal level, and so relieve any circulatory inefficiency, in spite of the apparent cerebral oedema.

\section{Post-mortem Findings}

Necropsy reports are available in all seven cases that died, and the findings are summarized below. The cases are grouped according to survival time.

Three cases died after five to six and a half hours; they had all very extensive deep burns and were not resuscitated in any way. These were: case 15, M. S., aged five years (60 per cent.); case 17, E. E., aged six years ( 75 per cent.); case 26, N. B., aged two years ( 60 per cent.).

The dura mater in cases 15 and 17 was tightly stretched, the surface vessels of the brain were intensely congested, and the convolutions were flattened, but there was no increase in the cerebellar cones. The kenous sinuses were engorged with dark fluid blood. In case 26 there were no signs of increased intracranial pressure. Microscopically 
all three showed venocapillary congestion (extreme in case 15) but no other change. Apart from slight cloudy swelling in case 26 , and glycogen vacuolation in the other two, there were no liver changes. The lungs in case 17 showed slight, and in case 26 marked congestion, with slight oedema. In case 15 there was no undue congestion but moderate emphysema. In the kidneys in cases 15 and 26 there was pink-staining albuminous material in Bowman's capsule and in the tubules, and case 15 also showed some fragmentation of the cytoplasm and nuclear pyknosis in the convoluted tubules. Case 26 showed cloudy swelling in the convoluted tubules. The bladder was empty in cases 15 and 26 and contained only a small amount of cloudy urine in case 17. All three showed slight haemoglobin staining of the intima of the aorta, presumably the result of intravascular haemolysis. The adrenals showed no abnormality in cases 15 and 17; they were not examined microscopically in case 26 .

Case 20, J. P., aged ten years, who had 50 per cent. very deep burns (electric and fire), died twenty-three hours after injury. (He was given intravenous plasma and saline, but insufficient to relieve the blood concentration; he became drowsy and irrational, had a convulsion, and died of respiratory failure after a lumbar puncture.) The brain weighed 1,400 g. (normal for age, 1,290 g.). The convexities showed slight convolutional flattening, the meninges were congested, and there was a wellmarked cerebellar pressure cone. The histological appearance was normal. The liver sinusoids were congested but cells showed no necrosis or other change. There was increased consistency of the lungs with marked congestion and intra-alveolar haemorrhages. The kidneys appeared macroscopically normal, but microscopically there was swelling of the glomeruli with narrowing of the glomerular space, the capillary loops being collapsed and empty, and the tubules showed cloudy swelling. There were a few c.cm. of clear urine in the bladder. The stomach was distended and filled with solid, partially digested food. (He drank $86 \mathrm{oz}$. of fluid in the twenty hours after admission and vomited only once; he apparently absorbed all this fluid, while practically no digestion or absorption of the solids occurred.) Gross venocapillary congestion was the only change in the adrenal glands.

Case 6, C. N., aged eight years, who had 60 per cent. deep burns, died after five days. She had widespread purulent bronchiolitis and bronchopneumonia, pyaemic abscesses in the thyroid gland and kidneys, and an acute splenic tumour. Her brain weighed 1,270 g. (normal for age, 1,273 g.). The dura mater was tightly stretched, the meninges oedematous, and the surface vessels injected. The convolutions appeared slightly flattened, and the cerebellum showed a slight pressure cone; the histological appearances were normal. The adrenal glands were congested but showed no other change.

The remaining two cases died after six and eight weeks in a grossly wasted state. These were case $16, M$. H., aged eight years, and case 27 , S. C., aged ten years, both of whom had 40 per cent. deep burns. Both showed widespread bronchopneumonia, with lung abscesses in case 16 . The liver in both cases showed fatty change, and in case 16 there was cloudy swelling and fatty change in the heart muscle. Both cases showed a septic spleen, and case 27 showed dehydration nephrosis.

\section{TREATMENT}

Treatment may conveniently be considered in three parts: firstly the local treatment, secondly the control of secondary infection and wasting, and thirdly the treatment of fluid loss by intravenous therapy.

\section{Local Treatment}

Immediately on admission the child was wrapped in a sterile sheet and pinned into it, so as to avoid as far as possible contamination from the atmosphere and from handling. The primary dressing in all but the very early cases of the series was delayed until relief and control of the fluid loss had been attained. This was considered to be an essential point because, not only is the concentration of the blood increasing steadily during the time taken over dressing, but there appears to be an increased rate of loss during the dressing, probably attributable directly to the trauma of cleansing, etc. Moreover, as has already been mentioned, general anaesthesia (open ether) relaxes the protective vasoconstriction and may produce a dangerous lowering of the blood pressure. Thirdly the warning signs are masked or disregarded in the post-anaesthetic period, i.e. rapid pulse is attributed to the operation, thirst and restlessness are unrevealed, and coldness and blueness of the extremities may be attributed to the effects of exposure and evaporation during the dressing, and so the condition may deteriorate badly before the danger is recognized.

The primary cleansing was carried out usually by 0.5 per cent. or 1 per cent. Cetavlon solution, and loose cuticle was removed. The dressing in the majority of cases was of tulle gras or vaseline gauze (sterilized in a hot-air oven at $160^{\circ} \mathrm{C}$. for one hour) with or without sulphanilamide or sulphathiazole powder. In a few cases a 5 per cent. sulphathiazole cream was used. Coagulation therapy was not employed at all in this series. It was thought important that a thorough cleansing of the skin for several inches around the affected area should be carried out, and that dressings should be applied with great care to avoid joins at places where much movement occurs, such as axillae, neck, and groins; these would appear to be very obvious precautions, but experience showed that they were often neglected. The bandage should be applied with equal care and with the aim of completely sealing off the lesion from the exterior. Adhesive tape applied liberally on top of the bandages was found very useful, and dressings could be left completely undisturbed for six or seven days without gaps 
developing. There is little doubt that much secondary infection is due to badly applied dressings and could be avoided with more care.

Dressings were done usually at five-day intervals, and, except in the mild cases, always under a general anaesthetic for the first three weeks. Sterile gowns, gloves, sheets, and towels were used. Sloughs were removed radically as soon as they could be without causing serious haemorrhage. In the later stages if there was secondary infection, and if the child would tolerate them, soap foam baths were given every other day, and proved useful in cleaning up the area for grafting. Some children, however, would not tolerate them (especially. if they had been scalded by falling into a bath) and loss of morale and confidence ensued if they were persisted in. A light general anaesthetic, administered by a skilled anaesthetist, even at three- or four-day intervals, is a great deal less harmful to a child than painful dressings producing terror and screaming. The usual anaesthetic was ethyl chloride induction followed by open ether with continuous oxygen, but intravenous pentothal was used with success in some of the older children. Rectal pentothal was given on one or two occasions and proved fairly satisfactory, but it should only be used by an experienced anaesthetist. Avertin was tried in a few cases but was not satisfactory, the child being noisy and struggling.

Skin grafting in fourth- and fifth-degree lesions was commenced as soon as a clean granulating surface could be produced, usually after six or seven weeks in an extensive area. Anaemia was fully corrected by blood transfusion before each grafting operation, and systemic penicillin was sometimes given for seven to ten days afterwards. In the later cases of the series 80 to 100 per cent. takes were obtained. The great difficulty lay in finding a sufficient donor area and in several of the children the calves were all that was available and they were used up to five times at three-weekly intervals.

\section{Control of Secondary Infection and Wasting}

As already indicated, this was a complex problem and varying success was met with, usually depending directly upon the extent of the lesion. If, as is still the case in most hospitals, burns and scalds have to be nursed in general wards, the avoidance of a certain amount of secondary infection in severe cases (i.e. 20 to 40 per cent. of the body surface) appears practically impossible. In the later part of this series all the children were able to be nursed in single cubicles or two-bedded side wards, and they certainly did better. It should be noted, however, that a ten-day course of penicillin was given to many cases (a) on admission and (b) after each skin graft, and the relative effects of this and of the isolation have to be considered. Sulphonamides and penicillin were widely used both locally and systemically, and were of great assistance.

Pyocyaneus infection was troublesome but it did not appear to have much adverse effect upon the grafting. Applications of 0.5 per cent. solution of phenoxetol were used with success against this organism, but after several days of this treatment in case 27 phenol-like substances appeared in the urine, so judgment must be reserved as to its suitability: Soap baths were also effective against the B. pyocyaneus.

In the treatment of severe wasting the problem of feeding remains a difficult and all-important one. Apart from deficient intake there appears to be a greatly increased calorie requirement, and high protein diets have been widely advocated. To work out a satisfactory diet, however, and to persuade the child to take it, were two quite separate problems. Sufficient amounts of meat, beans, cheese, etc., were rarely tolerated and if pushed led to nausea and vomiting. Milk and egg shakes appeared the best solution, but they were only acceptable in large amounts to a few children ; among working-class children in this district milk is generally disliked (probably because they are unaccustomed to it), and to persuade them to take it was often impossible.

The inter-dependence of appetite, morale, anaemia, and secondary infection is very complex and of great importance in the successful management of this recovery phase; a deterioration in any one direction has adverse effects in the other three, and a vicious circle is readily set up; similarly, improvement in one direction leads to improvement in the others. Thus the avoidance of painful dressings by the use of general anaesthesia improves morale, appetite, and resistance to infection; and the relief of anaemia by fresh blood transfusion not only produces a striking improvement in the psychological condition but improves the appetite, reduces the liability to secondary infection, and is essential for successful skin grafting. In short, all aspects of this phase must be kept constantly in mind and their inter-dependence remembered if a quick recovery is desired.

\section{Intravenous Therapy in the Phase of Fluid Loss and Concentration of the Blood}

It is probably correct to say that if death from circulatory failure consequent on reduced plasma volume and concentration of the blood does not occur within thirty-six hours of the accident, it is then unlikely. On the other hand, cessation of adequate therapy within the first thirty-six hours can be followed by a relapse which may be fatal. The early recognition of developing haemoconcentration is essential because reversal in the later stages is technically much more difficult, and because sudden collapse may occur in a child who has appeared fairly fit to the inexperienced eye, and death may supervene if one is taken unawares and unprepared. As has been shown above, there is nothing mysterious about the cause of death in this stage; close observation reveals that warning signs are present long before the so-called collapse occurs, 


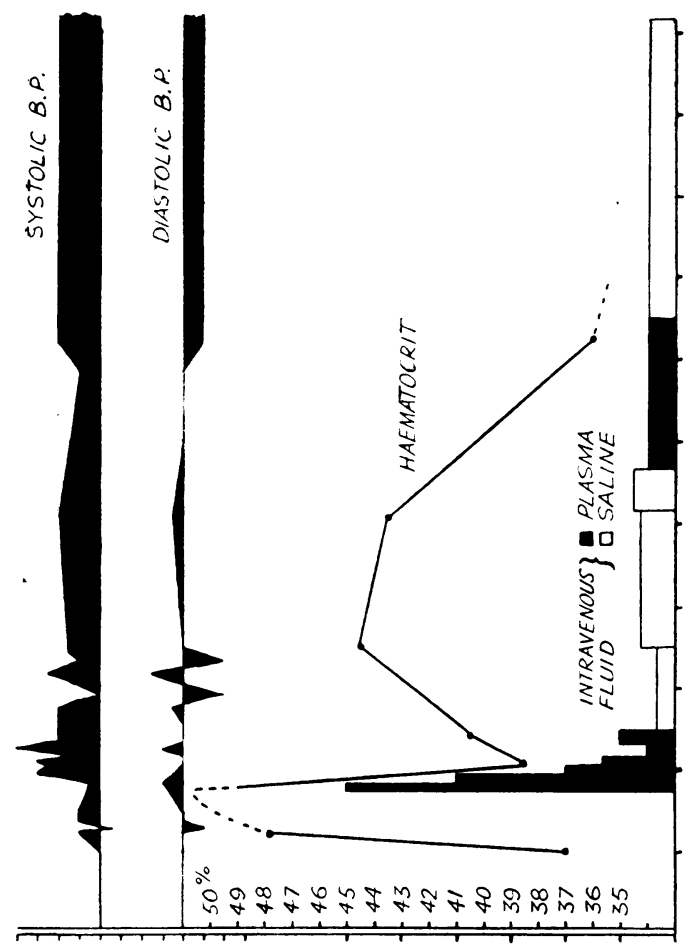

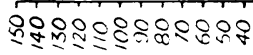

bH unu
\& \& \& \& \& \& 8 \& unoy wad uno
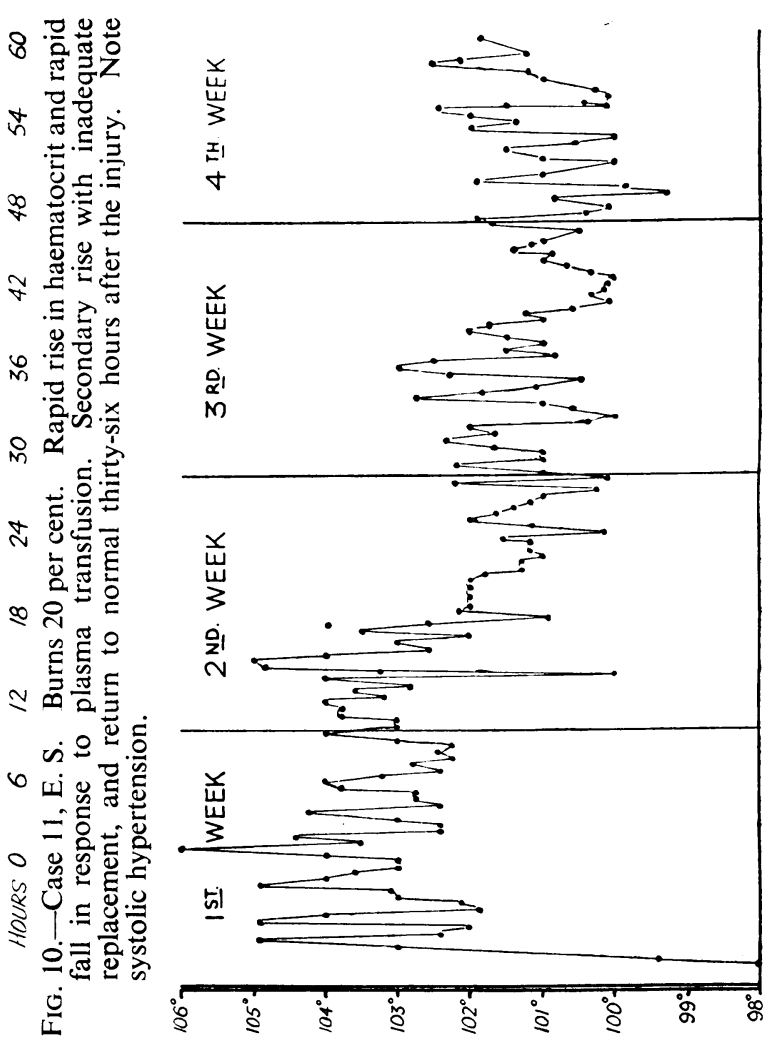

要

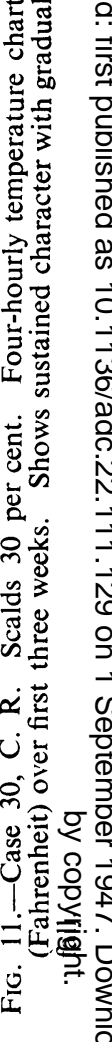

$\ddot{c}$

D

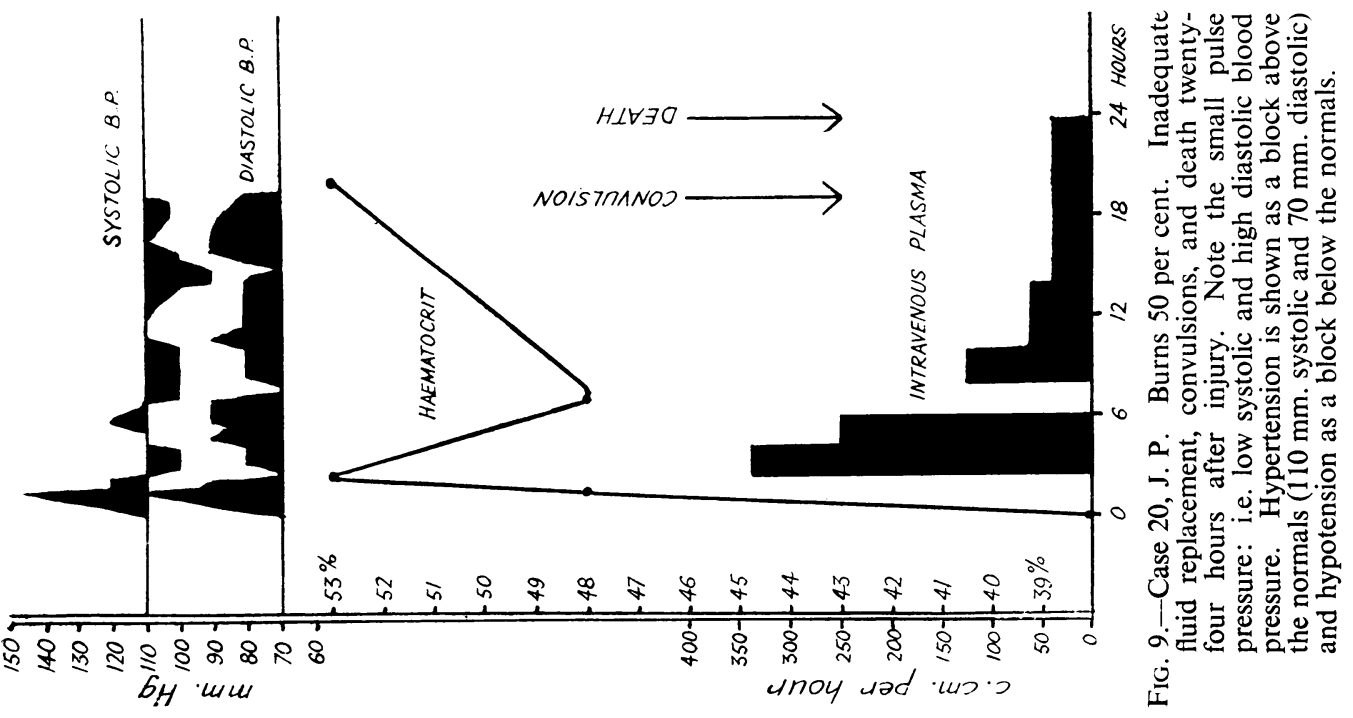




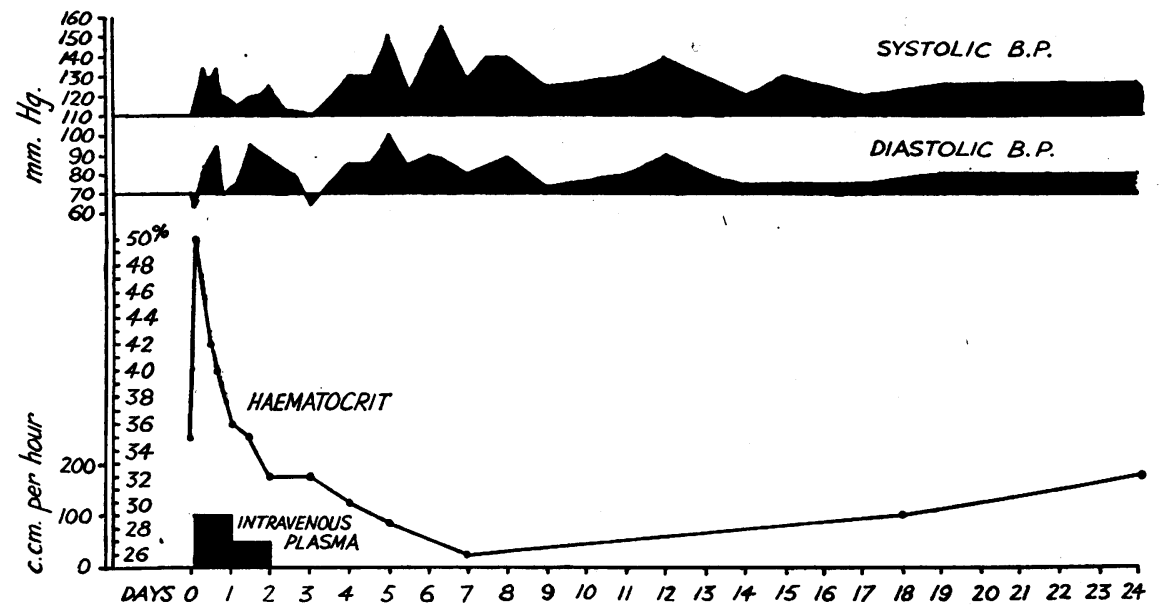

Fig. 12.-Case 30,C. R. Scalds 30 per cent. Extensive sloughing. Hypertension over the first three weeks, during and after intravenous plasma therapy.
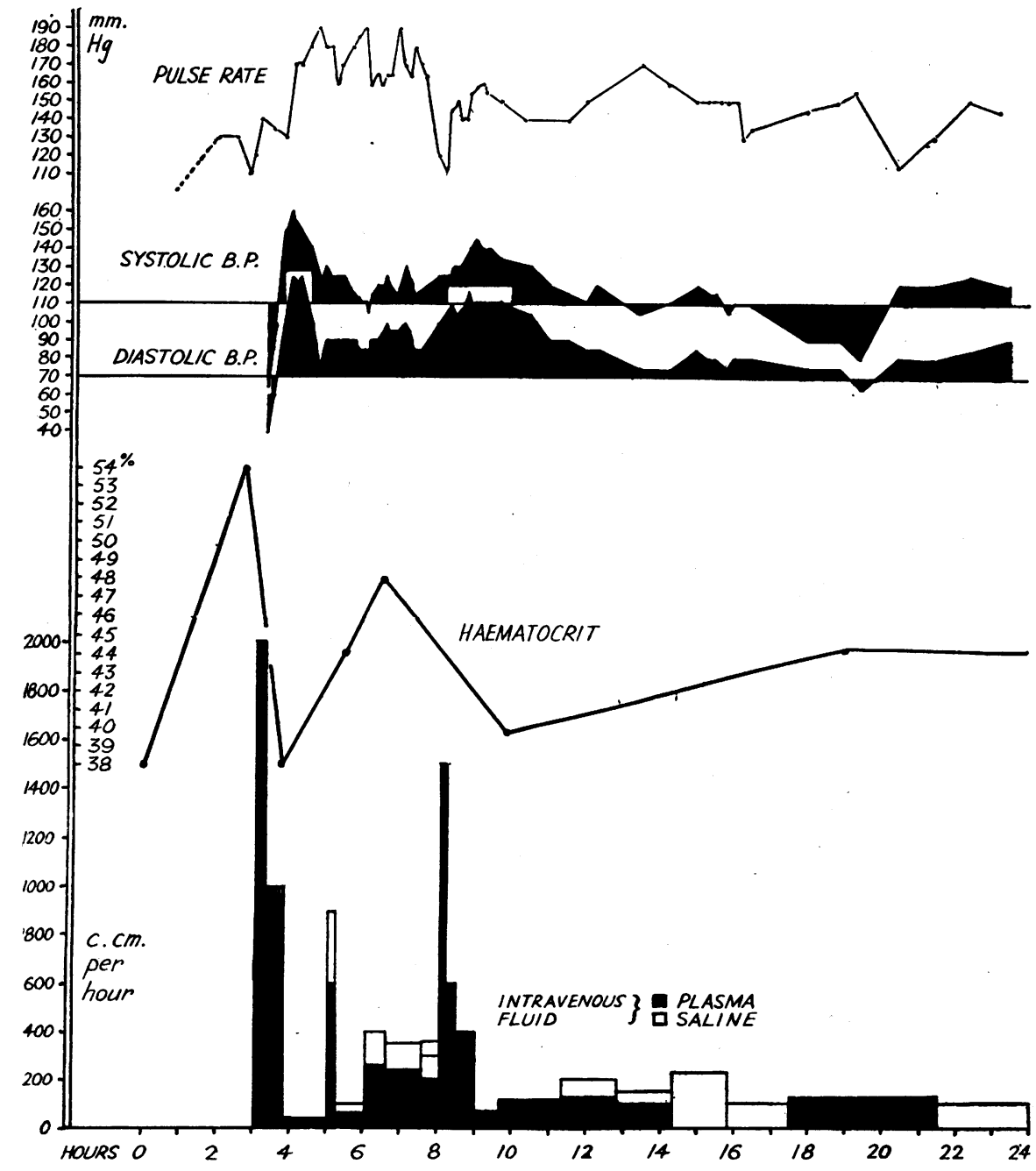

Fig. 13.-Case 16, M. H. Burns 40 per cent. The intravenous fluid in this case was given very irregularly (see text, page 147), and the resulting fluctuations in heart rate, blood pressure, and haematocrit during the first twentyfour hours are shown. 

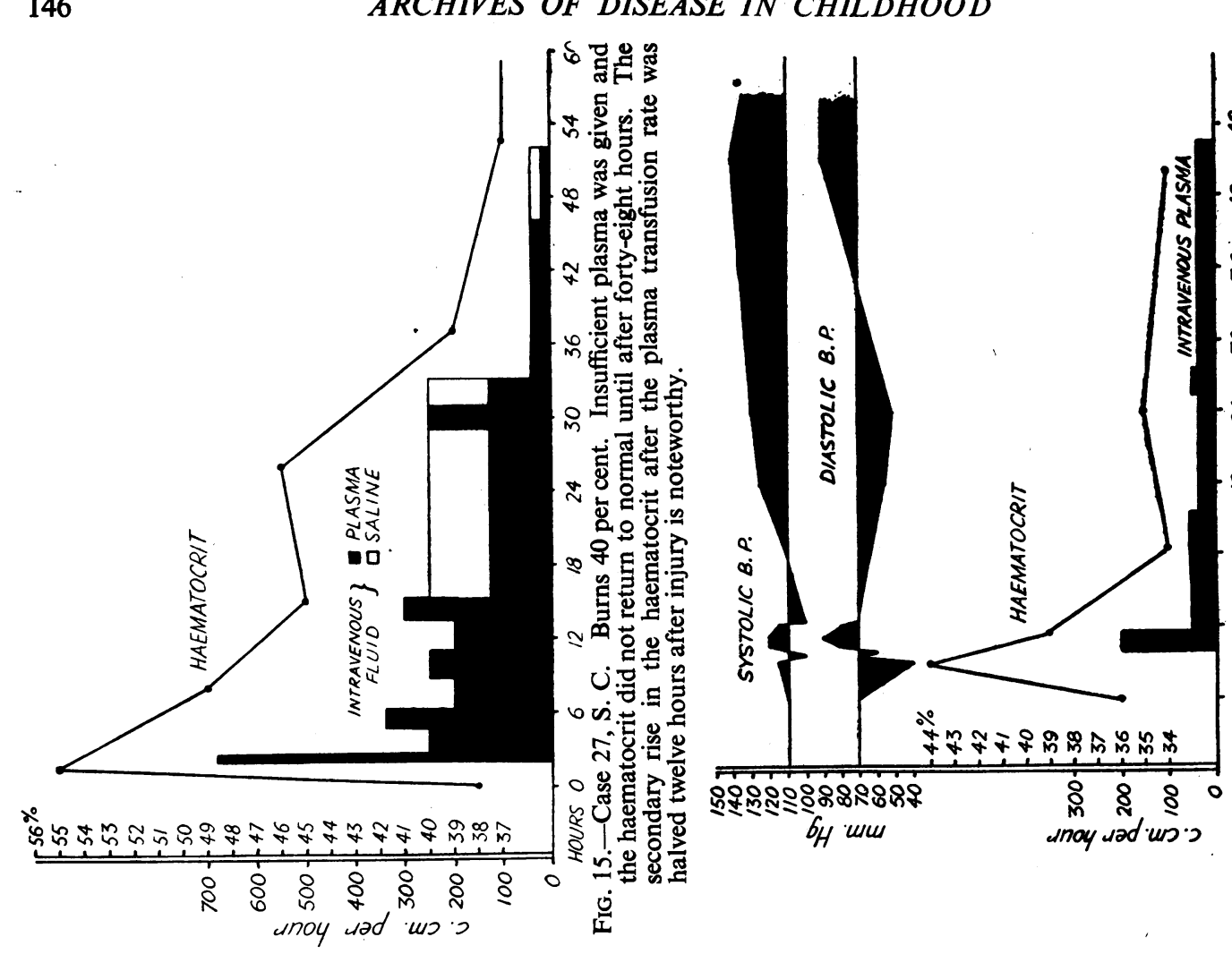

$\stackrel{0}{\rho}$

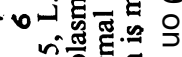

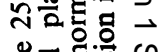
0 记 此导焉家 它

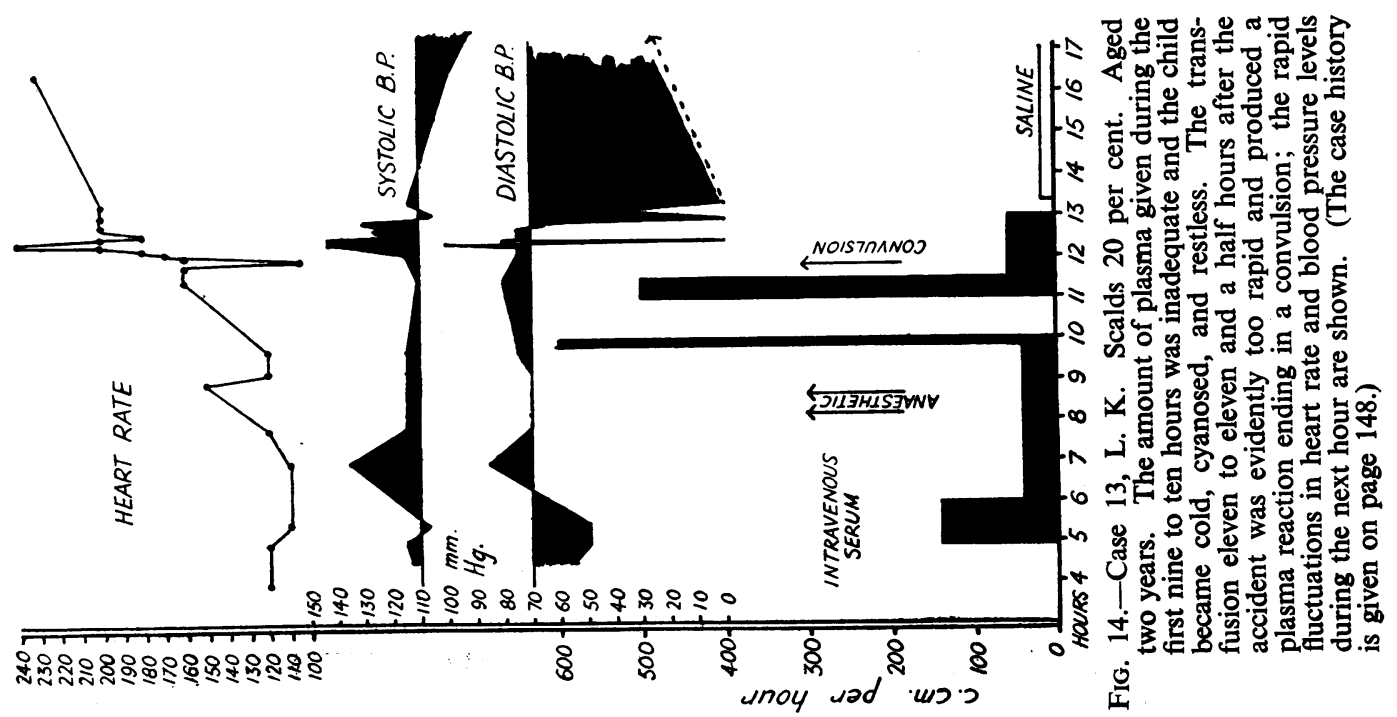

윰 


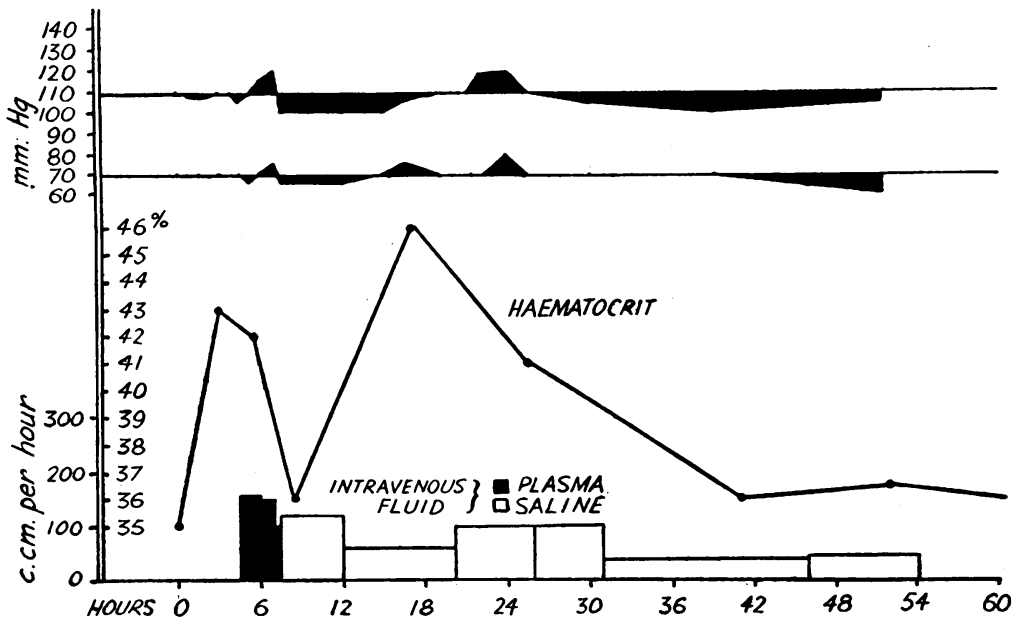

Fig. 17.-Case 8, E. D. Scalds 10 per cent. This case shows the fall in the haematocrit after plasma administration with a marked secondary rise when saline was substituted, and subsequent fall to normal after forty-two hours.

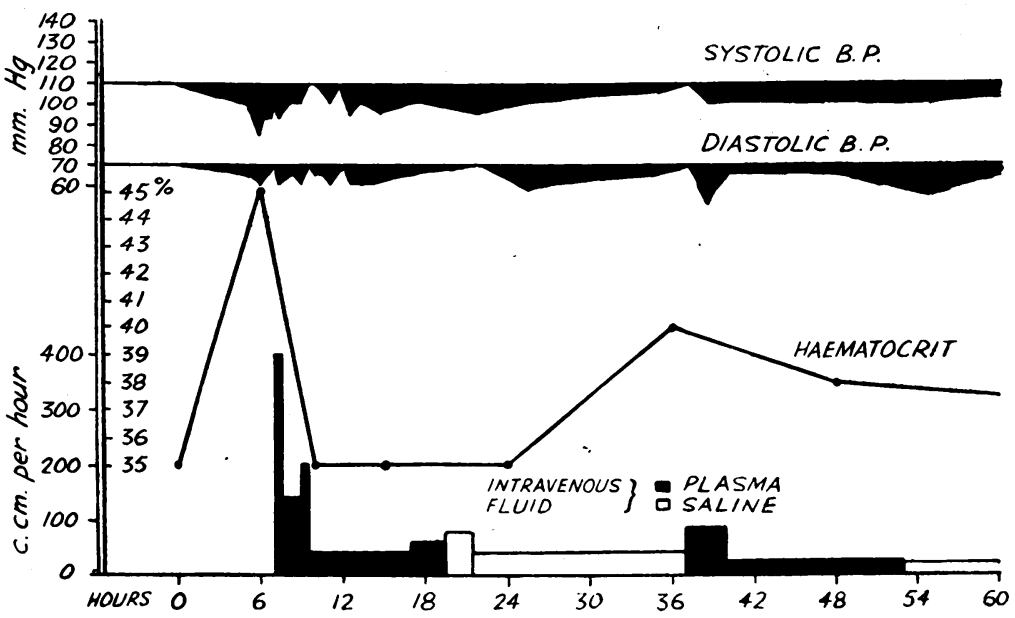

Fig. 18.-Case 12, M. B. Burns 20 per cent. The initial rise in haematocrit was corrected by plasma transfusion, but on substituting saline a secondary rise occurred and was not corrected by the end of forty-eight hours.

but failure to recognize their significance or to treat them promptly and adequately can have disastrous results.

In treating the first six or seven cases the need for intravenous fluid was judged largely by the clinical signs, and the results were checked against the blood findings. As already stated it soon became evident that the haematocrit value was a better index of the concentration of the blood than either the red cell count or the haemoglobin value, and it became the primary blood investigation. Over the period covering roughly cases 6 to 16 , progressively more reliance was placed on the haematocrit, and the intravenous fluid was given with the aim of obtaining a definite value for this. The fluid was still given, however, rather empirically, and the rate adjusted frequently according to the results obtained. In this way there was a good deal of overshooting and undershooting the mark, and the patient made a chequered progress towards an ultimately satisfactory result. The best example of this was seen in case $16, M$. H. (fig. 13).

Case 16. M.H. This child showed marked blood concentration at three hours, and would certainly have died without intravenous therapy. The fluid was given too rapidly, and although her haematocrit reached normal after only one hour, the signs of vasoconstriction persisted and the blood pressure rose steeply from 64/40 at three and a half hours to $160 / 120 \mathrm{~mm}$. $\mathrm{Hg}$ at four hours. Owing to the danger of a hypertensive fit, the rate of administration was cut down drastically, but it was two hours before the blood pressure fell to normal and vasodilatation occurred. By this time the haematocrit had risen again to an undesirable level and the pulse rate was 190. After $200 \mathrm{c.cm}$. of two-thirds strength serum in thirty minutes the rate fell to 160 . At seven hours 
she was given a general anaesthetic (open ether and oxygen) and the burns were cleansed and dressed. After this she was cold, and the rate of the drip was increased so that she had a further $600 \mathrm{c.cm}$. serum between the eighth and ninth hours. She became warmer after $500 \mathrm{c.cm}$., but then the vasoconstriction returned and the blood pressure rose to $145 / 110$. Eventually a compromise was struck, but the haematocrit remained on the high side for thirty-six hours. As it had been noticed that the hypertension subsided more rapidly when saline was given instead of serum, alternate $500 \mathrm{c.cm}$. of serum and saline were used. (The use of saline will be discussed later.)

Case 13. A similar state was seen in case 13, L. K. (fig. 14). This two-year-old child had second- and third-degree scalds over 20 per cent. of her body surface. The first haematocrit reading at six hours showed a deficiency of 30 per cent. of her total plasma volume; $150 \mathrm{c} . \mathrm{cm}$. plasma had already been given intravenously, so the actual loss must have been considerably greater. After dressing under an anaesthetic (seven to eight hours) she showed clinical signs of increasing plasma loss, and the rate of flow was speeded up at the tenth hour. Unfortunately no haematocrit readings were obtained during this period and treatment was guided by clinical criteria. The drip began to leak and had to be taken down, and there was a delay of one and a half hours before it was finally restarted. By this time the child was cold, cyanosed, and very restless and unco-operative, screaming and struggling during the venesection. The tissues were bloodless and the vein practically empty, and venespasm was so marked that considerable positive pressure (syringe and three-way tap) was required to start the flow; $300 \mathrm{c.cm}$. of serum was given in the next forty-five minutes (the total plasma volume at this age is about $500 \mathrm{c.cm}$.). The restlessness diminished but she remained cold and blue with pulse rate 160 and deep and rapid respirations. She then suddenly had a convulsion with generalized clonic spasms and vomited. After the fit the pulse rate fell to 104 per minute, she became warm all over, and the breathing became quiet and easy. No blood-pressure reading was obtained during the attack, but fifteen minutes later it was $115 / 75 \mathrm{~mm}$. Hg. In the next fifteen minutes the heart rate rose to 200 and the blood pressure to $145 / 100$, the extremities became cool, and the respirations grunting and distressed; she was noisy and irrational, and another convulsion was feared. However, the vasoconstriction again relaxed within five minutes, the skin becoming hot and the blood pressure falling, but the heart rate remained 180 to 200. The drip had been continued at about $80 \mathrm{c.cm}$. per hour during this time; at the thirteenth hour it was turned off completely and the child passed into a quiet sleep. It was then discovered that the rectal temperature was $105 \cdot 6^{\circ}$, which would explain the persistent tachycardia.
It seems likely that the above picture was the result of a reaction to plasma given too rapidly in an attempt to correct the concentration of the blood, which had been allowed to develop to a dangerous degree. In subsequent cases an attempt was mado to estimate the rate of fluid loss from the circulating blood, and to calculate from this the total requirements for the first twenty-four hours. (The method of calculation has been explained on page 132.) In the last ten cases of the series intravenous therapy was based entirely on such calculations, and the results, both regarding the smoothness of progress and the state of the child at the end of twenty-four hours, showed a considerable improvement. The fluid already lost was given in addition to the calculated hourly requirement, over the first three or four hours of treatment. That is, if at the start of treatment there was a calculated deficiency of $400 \mathrm{c.cm}$. of plasma, and if the rate of loss was estimated at $80 \mathrm{c.cm}$. per hour, for the first four hours of treatment the rate would be $180 \mathrm{c.cm}$. per hour, and thereafter $80 \mathrm{c.cm}$. per hour. By spreading out the administration in this way, rather than giving the $400 \mathrm{c.cm}$. rapidly at the start, plasma reactions of the nature of those described above were avoided.

Table 6 shows the summarized data in twenty-four cases (data were inadequate in three cases and four cases were not resuscitated). It gives the results of calculations, the fluid actually given intravenously, and the haematocrit values after twenty-four and forty-eight hours. In making the calculations it was presumed (a) that the child had normal blood volume and haematocrit values for its age or size at the time of injury, (b) that the rate of fluid loss was fairly constant during the first twenty-four hours at least, (c) that no significant dilution from tissue fluids occurred if the haematocrit was kept at a reasonable level, and (d) that there was no significant loss of red cells from the circulation. It appears from the results obtained that these presumptions were permissible for the purpose of guiding treatment.

Discrepancies occurred between observed and expected results and were seen particularly in cases $11,14,16,23,24,27$, and 28 .

In cases 23,24 , and 28 , a normal haematocrit value at the end of twenty-four hours was obtained with considerably less transfusion than the calculated requirements. However, in none of them was the normal value reached under twenty-four hours, whereas in cases 25,29 , and 31 , who were given the full calculated requirement, the normal was reached six to nine hours sooner (fig. 16, L. L.). The shape of the curves suggest that in the first group the rate of fluid loss had decreased towards the end of the first twenty-four hours, rather than that the original estimation of loss was too high. The occurrence of such diminished requirement becomes evident from serial haematocrit readings during therapy, and the rate of flow can be adjusted where necessary.

In cases 14, 16, and 27 the calculated fluid 


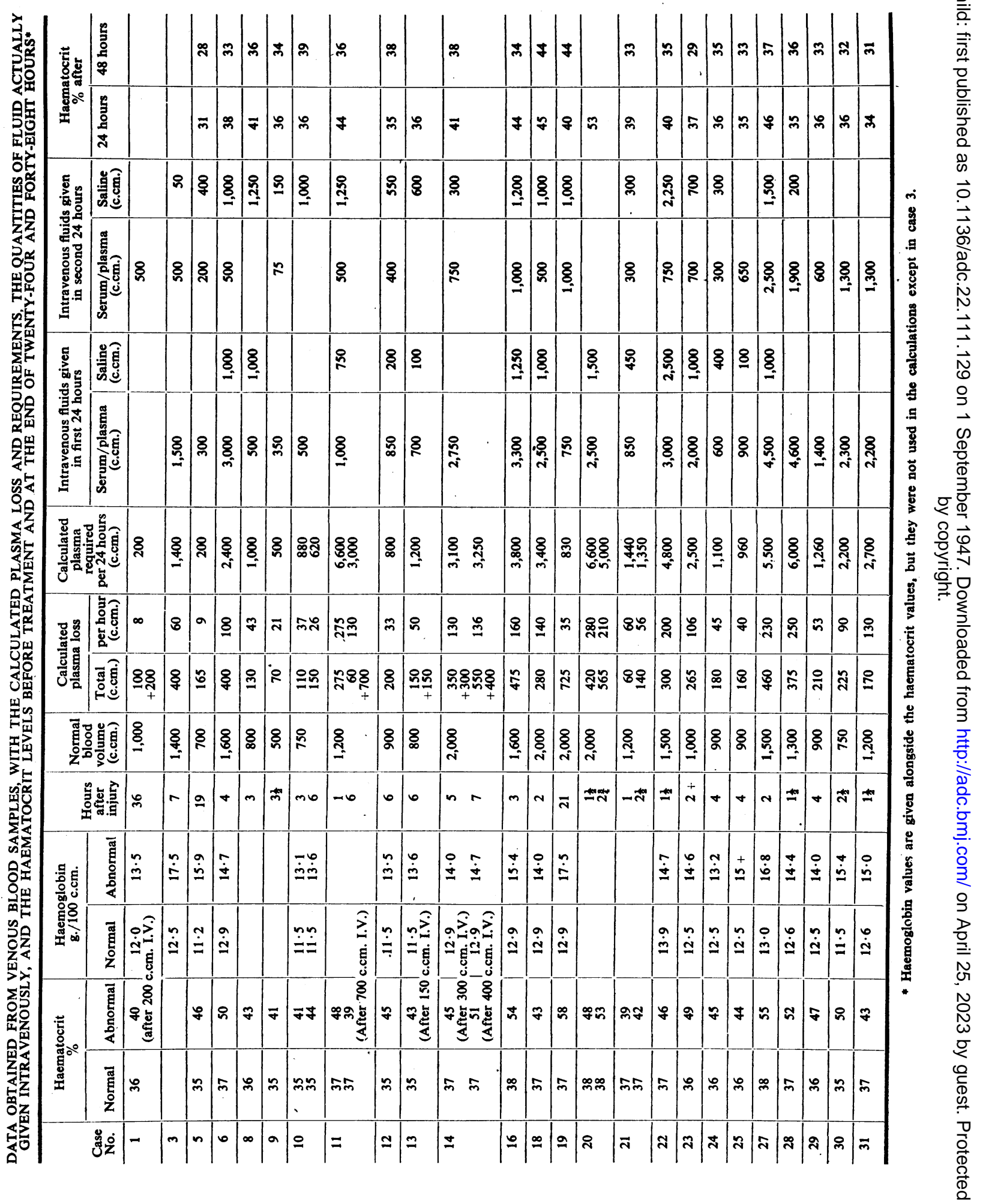


requirement was insufficient to produce a normal haematocrit value at the end of the first twenty-four hours (fig. 15, S. C.). But it will be seen from the table that the actual quantities given, which were decided by clinical criteria, were even further from the mark.

Case 11 shows the really outstanding discrepancy (fig. 10). The original haematocrit value was obtained from the whole blood specific gravity (Van Slyke copper sulphate method) and was not a direct measurement; also the exact time of injury was uncertain. Even so, the calculated requirement seems extraordinarily high. Therapy was guided by clinical criteria and the quantity given was obviously inadequate, but not to anything like the extent suggested by the calculation.

In the remainder of the cases the actual and expected results for the amount of fluid given showed good correlation. Where less than the calculated requirement was given the haematocrit remained raised, and where the full amount was given it had returned to normal after twenty-four hours. In many cases the haematocrit was purposely kept higher than normal, as it was at one time felt that the danger of cerebral oedema might be lessened in this way. However, for reasons already given, it is not now considered harmful and may be safer to relieve the haemoconcentration completely. Fig. 9, J. P., illustrates this point.

In practically every case charts were made of blood pressure readings, haematocrit levels, and intravenous fluids, but space does not allow of their all being included. Those shown have been picked to illustrate the points made in the text, but they are typical examples and they give a fair representation of the results obtained from different criteria of treatment.

Lastly the nature of the intravenous fluid must be considered. In many cases either a mixture of saline and serum or plasma, or alternate $500 \mathrm{c.cm}$. bottles of them were used, for the following reasons.

(1) There was a shortage of liquid serum and plasma and the dried plasma was not satisfactory for administration to children. (2) It was undecided whether saline was of value in correcting the concentration of the blood. (3) In some cases with oliguria $0 \cdot 2$ per cent. saline and 4 per cent. dextrose was given to increase the urinary output. (4) In some cases rather high plasma protein values were found and it was felt that the fluid lost from the burned areas may have a lower protein content than pure serum.

The first reason no longer exists. The second has been settled; it appears that saline solutions per se are of practically no value in relieving the abnormal concentration of the blood after burns and scalds. This was shown in cases $6,8,11,12$, $16,18,21,22$, and 27 . It is well illustrated by figs. 10,17, and 18, which show a rise in the haematocrit when saline was substituted for serum or plasma.

In the case of low urine output, where the circulation is satisfactory but where the patient cannot take fluids by mouth, there is an indication for giving saline intravenously, but it should be given in addition to and not instead of proteinous fluid.

The fourth reason only applied in certain cases; it may be advisable occasionally to dilute the plasma or serum with a certain amount of saline, but this can be stated to be generally unnecessary.

Between plasma and serum no obvious difference was noted, though the protein content of plasma must be less because of the citrate solution added when the blood is collected. The plasma was the more usually available and it proved quite satisfactory in use.

\section{SUMMARY AND CONCLUSIONS}

1. Thirty-one cases of burns and scalds in children were studied. An attempt was made to define the symptomatology of the different phases of the constitutional disturbance, and to correlate the physical signs with simple haematological data.

2. The main cause of illness and death in the early stages is reduction of blood volume by plasma loss. Early and adequate replacement by transfusion is essential for recovery in the type of case studied; therefore the recognition, assessment, and treatment of plasma loss is of prime importance during the first forty-eight hours.

The physical signs of reduced plasma volume are thirst, peripheral vasoconstriction, drowsiness, restlessness of spasmodic type, and eventually mental confusion and loss of consciousness. These signs constitute a specific indication for intravenous therapy and must never be disregarded. Hypotension is a late sign, and treatment should never be delayed pending its appearance.

3. The haematocrit value is a more sensitive index of fluid loss and a better guide to treatment than the clinical state, though they should always be considered in conjunction. Calculations from haematological data show that up to 30 per cent. of the plasma volume may be lost from the circulation before clinical deterioration is obvious, and death probably occurs when 60 to 70 per cent. of the plasma has been lost. Allowing for the rapidity with which the concentration of the blood can increase, it is therefore unsafe to be guided solely by the clinical state, unless the child is under constant and skilled observation, and even then the margin of safety is considerably greater if haematological data are utilized.

4. Certain 'toxaemic' signs may be seen during the second twenty-four hour period and in the succeeding weeks. Their nature is not understood but they do not appear to be due to either fluid loss or secondary infection. They are: (a) sustained pyrexia and hyperventilation; (b) moderate, sustained hypertension ; (c) nervous signs suggesting 
increased intracranial pressure and possibly due to cerebral oedema.

Hypertension occurs frequently in cases of burns and scalds, both during the administration of plasma and serum and in the succeeding weeks. There appears to be a definite individual liability to it.

Cerebral oedema probably occurs in severe cases (clinical and post-mortem evidence) and is not due to overadministration of intravenous fluids, because the picture is seen in inadequately resuscitated or unresuscitated cases.

5. The problems of the recovery period are secondary infection and wasting and they are interrelated. The maintenance of good morale during this period is of paramount importance, and the relief of anaemia by blood transfusion and the avoidance of painful dressings are decidedly helpful in this respect.

6. The blood urea shows only slight or no increase (the highest level recorded in the series was $80 \mathrm{mg}$. per $100 \mathrm{c.cm}$.), and the rise is usually associated with inadequate fluid intake or with wasting.

7. Sulphonamides are absorbed rapidly from the burned areas during the first two days and care must be taken in their application.

8. The leucocytes may show a rapid rise to the region of 30,000 or 40,000 within a few hours of the injury. The leucocytosis subsides gradually over three or four days and is probably a specific reaction to injury. Secondary rises in relation to infection are less marked and occur later.

9. Convulsions may be symptomatic of three conditions: (a) circulatory inefficiency from untreated plasma loss; (b) hypertension during plasma and serum reactions; (c) the cerebral disturbance of the 'toxic' phase.

10. Saline solutions are of little or no use in the relief of marked plasma loss, but may need to be given in addition to serum or plasma where the urine output is low and the child unable to drink.

The occurrence of burns and scalds is a social problem. About 90 per cent. of the accidents occur in the home. Many could be avoided by the provision of proper fireguards or space for the children to play in away from the kitchen hearth. Recovery from a case of any severity is necessarily a long and painful process, lasting many weeks or months. The constitutional disturbance is severe and may endanger life in several ways. Any measure taken to improve treatment can never remotely approach in value any measure taken towards prevention.

I should like to thank Professor J. C. Spence of the Children's Department, Royal Victoria Infirmary, Newcastle-on-Tyne, and Dr. R. T. Grant and Dr. E. B. Reeve of the Clinical Research Unit, Guy's Hospital, for their valuable help and advice, and also the medical and nursing staff of the Royal Victoria Infirmary for their co-operation and assistance.

\section{REFERENCES}

Bourdillon, R. B., and Colebrook, L. (1946). Lancet, 1,561 .

Brines, J. K., Gibson, J. G., and Kunkel, P. (1941). J. Pediat., 18, 447.

Colebrook, L. (1946). Mon. Bull. Min. Hlth. and E.P.H.L.S., p. 214.

Phillips, R. A., Van Slyke, D. D., and others (1944). Bull. Hyg., Lond., 19, 140.

Robinow, M., Hamilton, W. F., Woodbury, R. A., and Volpitto, P. P. (1939). Amer. J. Dis. Child., 58, 102.

Wilson, W. C., MacGregor, Agnes, R., and Stewart, C. P. (1938). Brit. J. Surg., 25, 826.

Wintrobe, M. M. (1942). Clinical Haematology. London. Henry Kimpton. p. 72. 


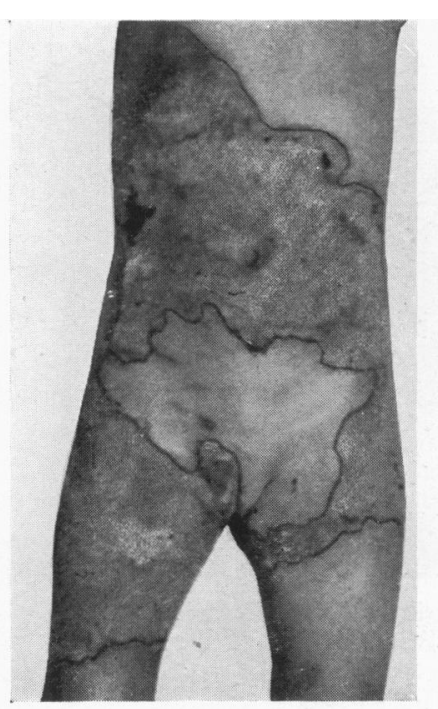

(1a)

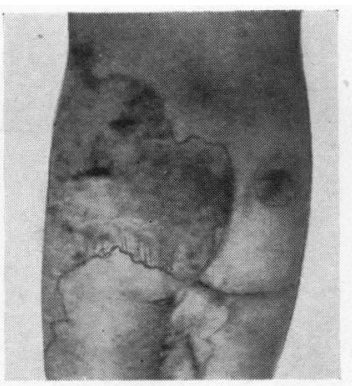

(1b)

Fig. 1.-Case 1, M. M. Photographs taken on tenth day, showing the comparatively small area involved, although she was critically ill from fluid loss in the first thirty-six hours.

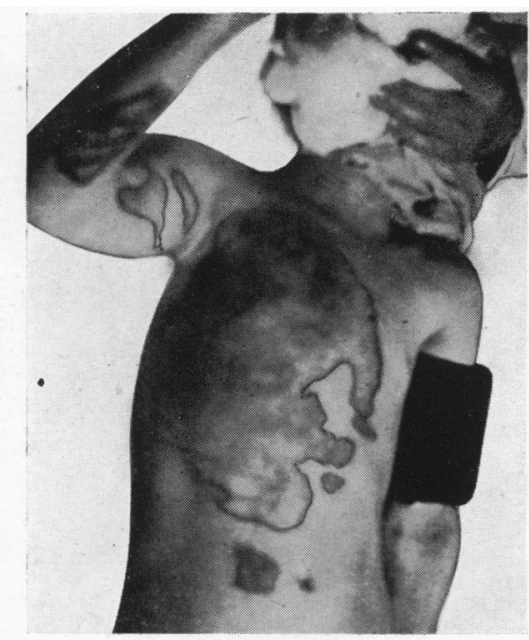

(2a)
FIG. 3.-Case, 15, M. S. Extensive fourth- and fifth-degree burns. No resuscitation. Death six and a half hours after accident.

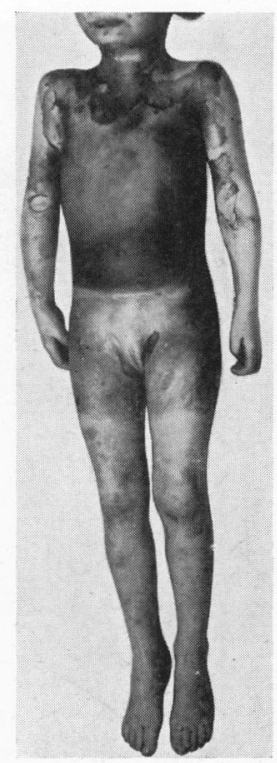

(3a)

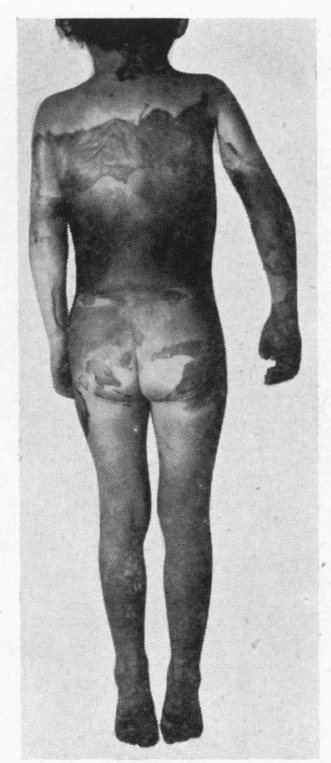

(3b)

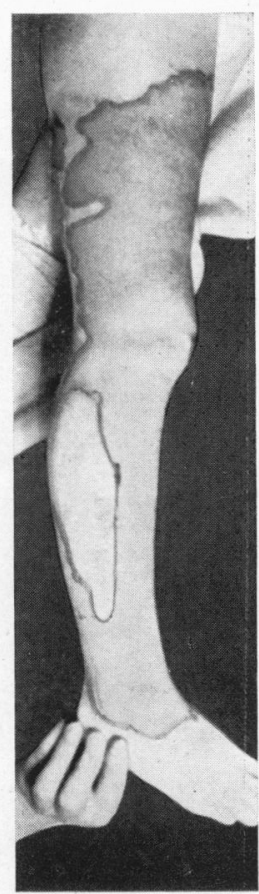

(2b) 


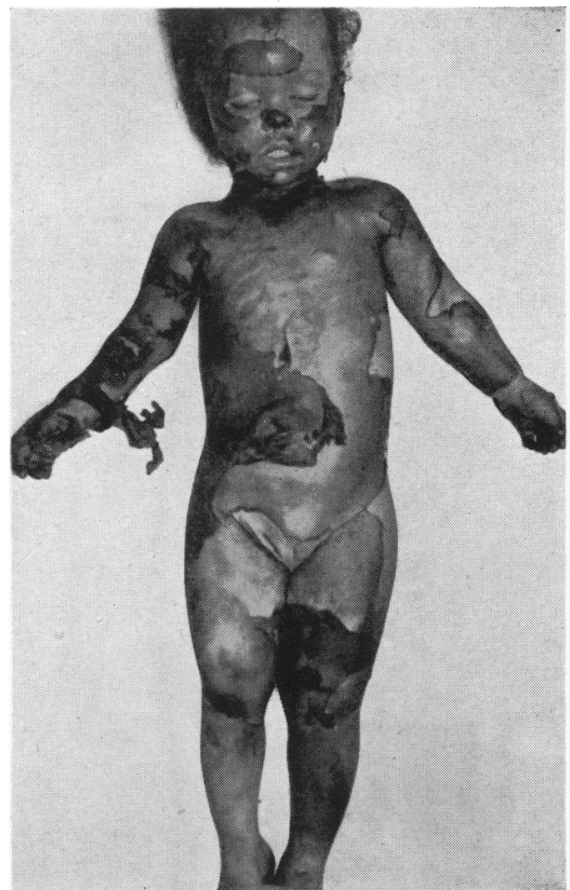

(a)

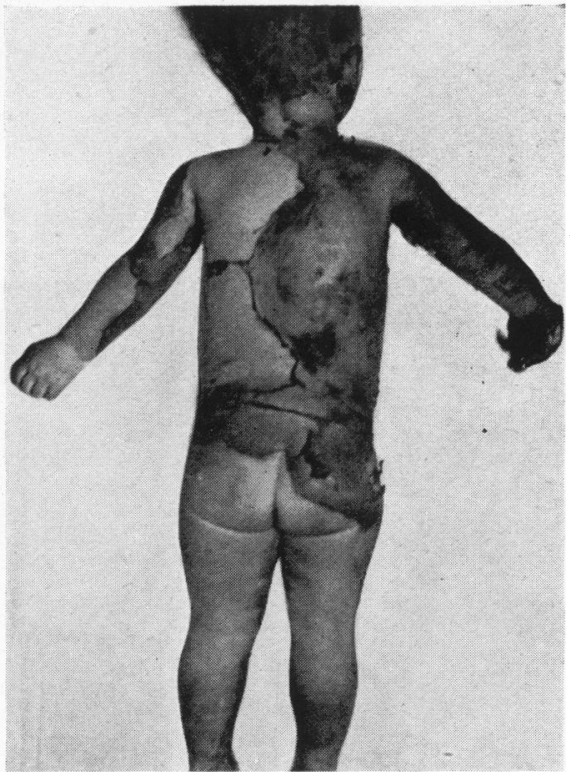

(b)

Fig. 4, a and b.-Case 26, N. B. Extensive fourth- and fifth-degree burns. No resuscitation. Death six hours after accident.

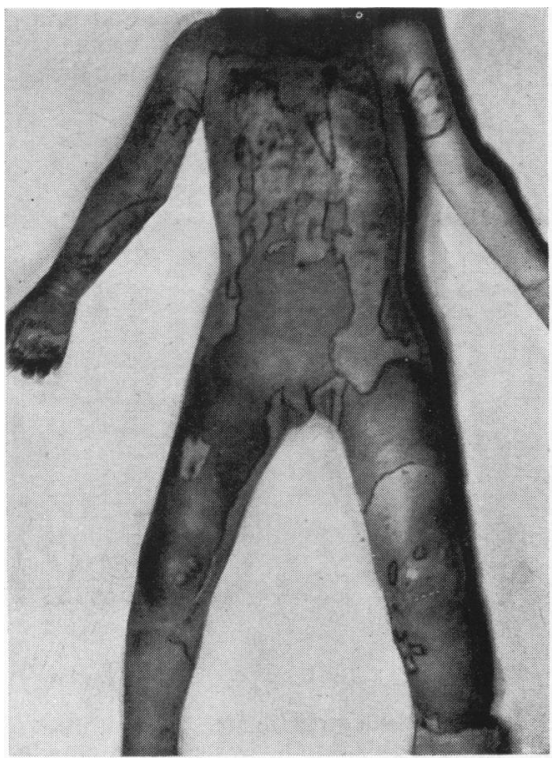

(a)

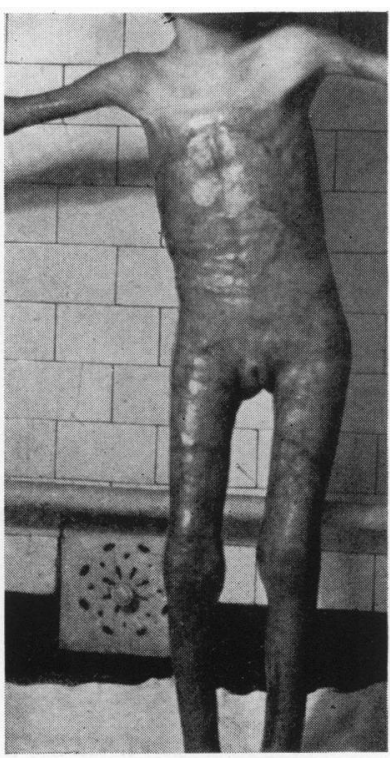

(b)

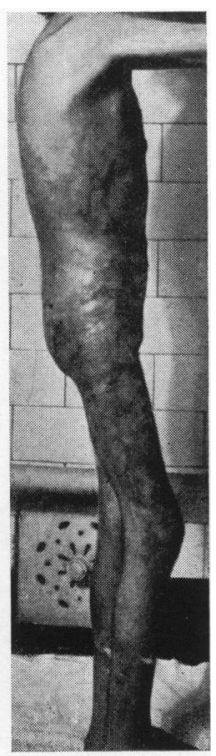

(c)

Fig. 5.-Case 28, M. W. Extensive fourth- and fifth- degree burns, (a) day of admission, and (b and c) three and a half months later, showing complete healing after repeated Tiersche grafting (the whole area sloughed). 


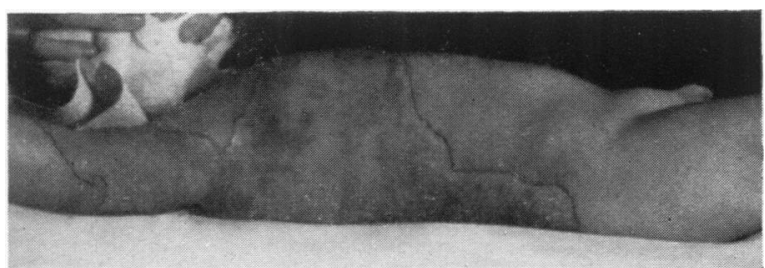

(6a)

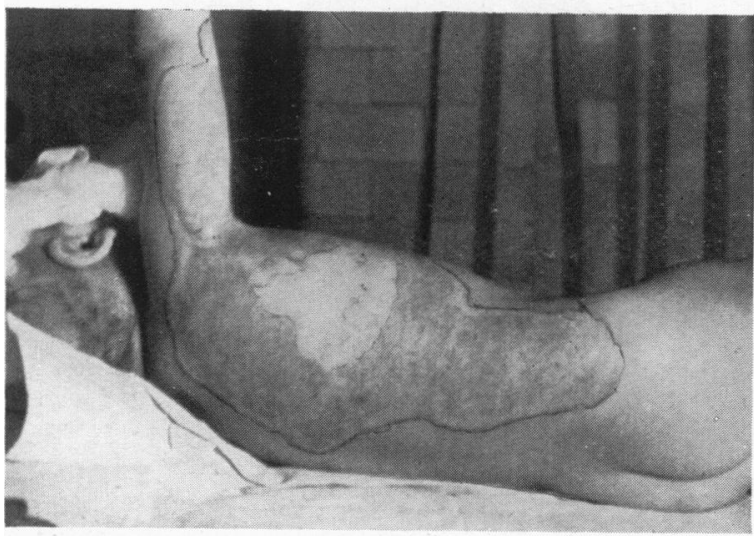

(6b)

Fig. 6.-Case 29, A. P. Scalds caused by boiling water, showing central sloughing on sixth day.

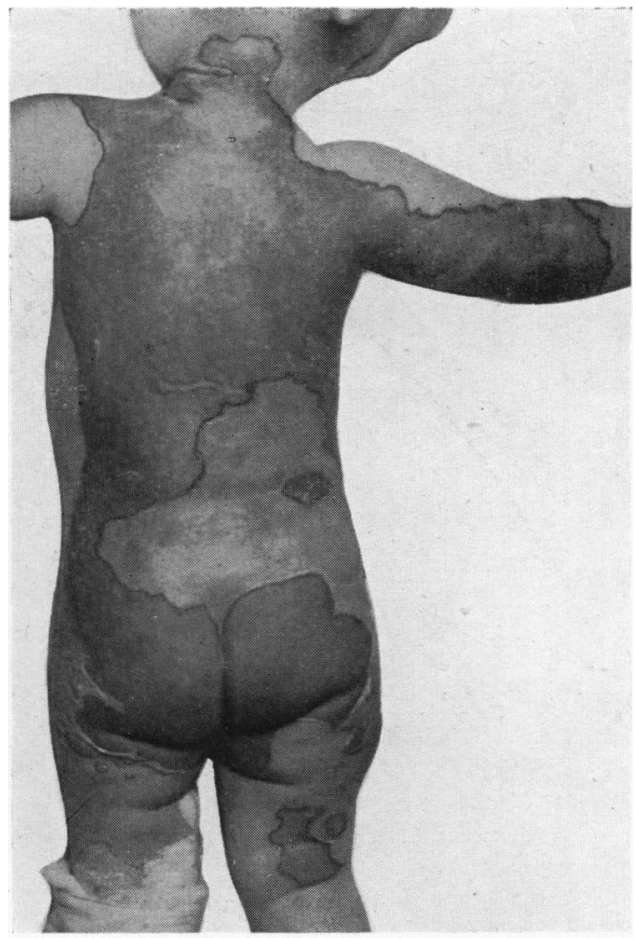

(7)

Fig. 7.-Case 30, C. R. Extensive deep scalds photographed on the fifth day. The entire area sloughed and required grafting. The child was very ill but ultimately made a complete recovery. (See also figs. 11 and 12.)

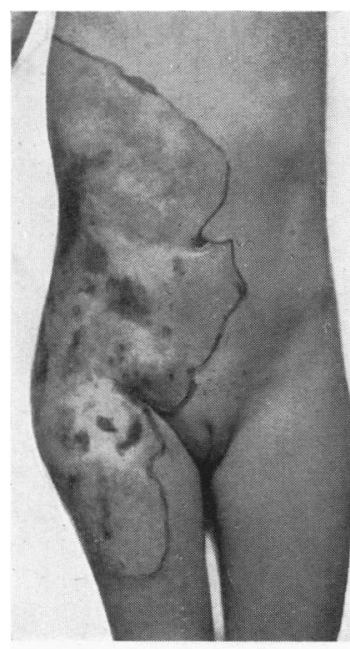

(8a)

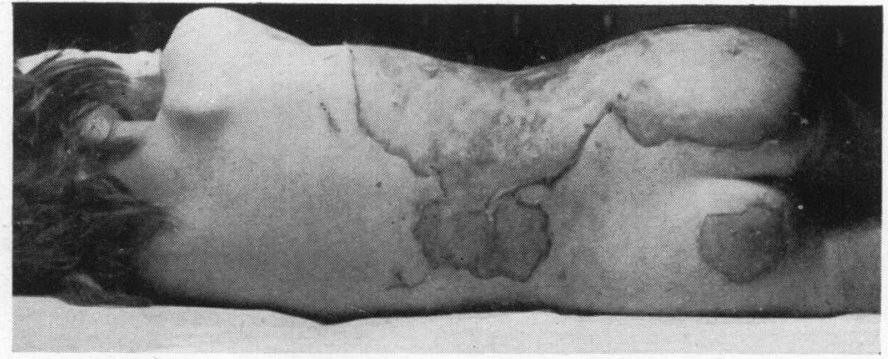

(8b)

FIG. 8.-Case 31, E. L. Fourth-degree burns. Appearance a few hours $\boldsymbol{0}$ after the accident-white with some brown charred cuticle. Complets sloughing and successful skin grafting subsequently. 